January 2019

"Liquidity Formation and Preopening Periods in Financial Markets"

Jieying Hong and Sébastien Pouget 


\title{
Liquidity Formation and Preopening Periods in Financial Markets
}

\author{
By Jieying Hong* and SÉbastien Pouget** \\ ESSEC Business School* Toulouse School of ECONOMICS**
}

January 7, 2019

\begin{abstract}
This paper studies the role of preopening periods in liquidity formation and welfare in financial markets. Because no transaction occurs during these preopening periods, their economic significance could be questioned. We model a market where costly participation and asymmetric information prevent latent liquidity from being expressed. At equilibrium, risk-averse insiders use preopening periods to better coordinate supply and demand of liquidity by communicating liquidity needs, thus improving welfare. Partial or full communication of private signals by the insider with the asset at preopening periods does not always enhance liquidity formation, but improves welfare through reducing adverse selection risk faced by the outsider and increasing the likelihood of her entry. Our findings have implications for portfolio management and the design of financial markets.
\end{abstract}

Key words: Asymmetric Information, Liquidity Formation, Preopening Periods

JEL classification: G14, D82

\section{INTRODUCTION}

Many stock markets around the world (e.g. NASDAQ, Toronto Stock Exchange, Paris Bourse, Milan Borsa, and Madrid Borsa) allow traders to place non-binding orders before actual trading. These orders result in tentative prices that are publicly disseminated. Because preopening periods do not give rise to transactions, their economic significance could be questioned. However, the empirical and theoretical literature in market microstructure has shown that, despite the absence of transactions, preopening periods reveal information. Biais et al. (1999), Cao et al. (2000), Barclay and Hendershott (2003), Barclay and Hendershott (2008), Jiang et al. (2012) and Pagano et al. (2013) empirically document that indicative prices in preopening periods reflect learning of stocks equilibrium valuation in different markets. Vives (1995) and Medrano and Vives (2001) propose models to show that tentative prices reveal information if the orders 
placed during the preopening period can be executed with a non-null probability. Less attention, however, has been paid to the potential influence of preopening periods on liquidity formation and welfare. This paper proposes a theoretical model to address these issues.

We consider a theoretical model with one risky asset and two traders: an insider and an outsider. The insider receives an endowment shock, which grants him the risky asset with a positive probability. The insider is risk averse and the outsider risk neutral, it is thus optimal for the insider to sell the risky asset to the outsider to hedge his position and for the outsider to provide liquidity to the insider. Our analysis is based on two premises. First, we consider that the liquidity provider (the outsider) has to pay a cost to participate in the market. This cost can be thought of as an opportunity cost related to the time spent learning about market conditions. Second, we consider that there are information asymmetries between traders. In particular, we assume that the insider possesses superior information not only on his liquidity need (endowment shock) but also on asset value which can be high or low. These two frictions magnify the difficulty of providing liquidity to the market.

In this framework, the insider uses the preopening period to place non-binding orders to communicate his liquidity needs and/or private signals on asset value to the outsider. Since preopening periods do not translate into actual trades, the conditions under which the insider has incentives to truthfully reveal his information to the outsider is a major concern. In this paper, we consider fifteen pure strategies that the insider can take at preopening periods to partially or fully reveal his information on liquidity needs and/or private signals. We find three strategies dominating others in equilibrium. The first strategy is preannouncement of liquidity needs. The truthful communication of liquidity needs is always an equilibrium since no conflicts of interest between the traders arises regarding the endowment shock. The other two strategies include partial and full communication of private signals by the insider with the asset. The truthful communication of private signals concerning asset value is not always feasible, because the insider with the asset receiving low quality signal may have incentives to mimic the high quality signal.

The truthful transmission on asset values is only feasible under two scenarios. One is when the gains from trade are small and the adverse selection very severe. In this case, the outsider 
optimally chooses to shut down trading with high quality asset in the trading stage. Therefore, the insider will not obtain any informational rent regardless of his private signals on asset values, which prevents him from manipulating the information at the preopening stage. The other situation is when the entry cost is sufficiently high, in which case the outsider can credibly punish the lying behavior of the insider by staying out of the market given the preannouncement by the insider with the asset that the signal is of high quality. This contingent no entry decision at the preopening stage works as a punishment mechanism to ensure that the insider has no incentive to lie.

We further study the impact of preopening periods on liquidity formation and welfare. On the one hand, we find that the insider uses the preopening period to communicate his liquidity shocks that need to be hedged. This allows the outsider to make a contingent entry decision based on liquidity shocks, which saves her entry cost, coordinates the supply and demand of liquidity and reduces the likelihood of market breakdowns. Therefore, preannouncing liquidity needs improves social welfare. On the other hand, the insider with liquidity needs might also partially or fully reveal his private signals concerning asset value during the preopening period. It reduces the adverse selection risk faced by the outsider. We find that this type of communication improves social welfare but may sometimes reduce liquidity formation.

Our model is inspired by Laffont and Maskin (1990) in that it analyzes trading using contract theory. Our approach differs from theirs in two dimensions. First, in lieu of a risk-neutral insider, we consider a risk-averse insider with two trading motivations: informed speculation and hedging, in line with, e.g., Bhattacharya and Spiegel (1991) and Biais et al. (2000). Second, we study the role of alternative market mechanisms, namely the presence or not of a preopening period, and their welfare implications. The role of the preopening period in coordinating supply and demand of liquidity is in line with the theoretical analysis of sunshine trading by Admati and Pfleiderer (1991). We complement their study in three aspects. Admati and Pfleiderer (1991) i) model the traders preannouncing their orders as noise traders, ii) consider that preannouncing traders are always uninformed, and iii) do not specify the mechanism through which preannouncement reaches the market. In contrast, we study a market game where all traders are utility maximizing agents. This allows us to study the strategic dimension of prean- 
nouncement and its welfare implications. We also consider that the preannouncing traders can have superior information. This allows us to investigate the role of preannouncement in price formation and information revelation. Finally, we explicitly model the market mechanism that can accommodate preannouncements, i.e., the preopening period.

Our paper is also related to the theoretical analyses of preopening periods. Vives (1995) and Medrano and Vives (2001) show that tentative prices can reveal information if the orders placed during the preopening period can be executed with a non-null probability. We complement these findings in two ways: i) we show that, even when agents can place non-binding orders, preopening periods can generate useful pricing information, and ii) we address the issue of liquidity formation. Baruch (2005) studies the impact of transparency on market openings by comparing closed and open limit-order books. Our preopening period has a similar spirit to his open limit-order book consideration.

Our result that insiders might have an incentive to reveal their private information during a round of preplay non-binding communication echoes the findings of Spatt and Srivastava (1991). They show that truthful preplay communication in initial public offerings can be part of an optimal auction mechanism. In their model, traders' incentives to disclose private information are related to the fact that announcing true valuations does not affect prices, but maximizes traders' probability to receive the asset (in the spirit of a second price auction). In contrast, riskaverse traders in our model have an incentive to truthfully reveal information because trading strategies endogenously preclude manipulation to be profitable.

The rest of this paper is organized as follows: Section I. describes the model. Section II. presents the equilibrium analysis, Section III. analyzes how the preopening period affects liquidity formation and welfare, and Section IV. concludes by offering implications for portfolio managers and market organizers. Proofs are in the Appendix.

\section{THE MODEL}

Consider a financial market for a risky asset with value $\tilde{v}=\tilde{\theta}+\tilde{\varepsilon}$. $\tilde{\theta}$ is a random variable that takes the values $\theta_{L}$ and $\theta_{H}$ with equal probability, where $\theta_{H}>\theta_{L} . \tilde{\varepsilon}$ is a centered normal variable with variance $\sigma^{2}$, i.e., $\tilde{\varepsilon} \sim N\left(0, \sigma^{2}\right)$. 
There are two investors: one insider (referred to as he and denoted by I), and one outsider (referred to as she and denoted by $\mathrm{O}$ ). The insider is risk averse with a negative exponential utility function with constant absolute risk aversion parameter denoted by A. The outsider is risk neutral.

The timeline of the trading in the financial market is as in Figure 1.

[Figure 1 here]

At the beginning, the insider receives an endowment shock $\tilde{e}$, which takes the value 1 with probability $\lambda$ and the value 0 with probability $1-\lambda$. When the endowment shock is 1 , the insider owns the risky asset. When the endowment shock is 0 , the insider does not own the asset. We assume that the asset is divisible. In addition, the insider privately observes a signal $\tilde{s}$, which is correlated with $\tilde{\theta}$.

$$
\begin{aligned}
& \operatorname{prob}\left(\tilde{s}=\theta_{L} \mid \tilde{\theta}=\theta_{L}\right)=\operatorname{prob}\left(\tilde{s}=\theta_{H} \mid \tilde{\theta}=\theta_{H}\right)=p \\
& \operatorname{prob}\left(\tilde{s}=\theta_{H} \mid \tilde{\theta}=\theta_{L}\right)=\operatorname{prob}\left(\tilde{s}=\theta_{L} \mid \tilde{\theta}=\theta_{H}\right)=1-p
\end{aligned}
$$

where $p>\frac{1}{2}$. Equation (1) indicates that if $\tilde{\theta}=\theta_{L}\left(\tilde{\theta}=\theta_{H}\right)$, the insider observes a signal $\theta_{L}$ $\left(\theta_{H}\right)$ with probability $p$ and a signal $\theta_{H}\left(\theta_{L}\right)$ with probability $1-p$. Since $p>\frac{1}{2}$, the signal is informative.

After the insider privately observes his endowment shock and the signal on the asset value, there is a preopening period where the insider can submit a non-binding limited order $(q, l)$, where $q$ represents a quantity and $l$ is a limit price. After observing $(q, l)$, the outsider can decide whether or not to enter the market with an entry cost $c$. As in Grossman and Miller (1988) and Admati and Pfleiderer (1991), if she decides to participate in the market, the outsider incurs a cost $c$. This cost can be interpreted as an order processing cost. It can also be thought of as an opportunity cost related to the time spent learning about market conditions or the cost of freeing up capital for trading. In the meantime, the insider perfectly observes the value of $\tilde{\theta}$. This assumption indicates that the information set of the insider can evolve during the preopening period. This assumption comes from the fact that traders can keep updating their information set from different sources during the preopening period. It also makes our setup more general since 
the case where the insider does not change his information set corresponds to a special scenario in our model that the signal received by the insider before the preopening period is perfectly informative. In addition, with this assumption, our model can generate some interesting results in Section II.(c) on how the informativeness of the insider's private signal affects the parameter range of the credible information transmission regarding asset values during the preopening period.

Given that the outsider enters the market and pays the cost $c$, the game proceeds to the trading period. The outsider submits a menu of binding limit orders denoted by $(\alpha, P)$ where $\alpha$ is a vector of quantities and $P$ is a vector of associated limit prices (If the insider were to submit limit orders at the trading stage, we would be in a signaling game. This would induce equilibrium multiplicity.). The insider chooses to trade against one of the limit orders submitted by the outsider. This decision is denoted by $m$ where $m=i$ represents that the insider chooses to execute the order $\left(\alpha_{i}, P_{i}\right)$. In our setup, the insider has four types since he has private information on both his endowment shock and asset value. The revelation principle allows us to restrict our attention to the case where the outsider submits four binding limit orders at the trading stage. Limit orders with 0 quantity represent no trading. Finally, the trading ends. The value of asset $v$ becomes publicly observable and consumption occurs.

In this game, an insider strategy is a pair of mappings $(q, l):\left(\{0,1\},\left\{\theta_{L}, \theta_{H}\right\}\right) \rightarrow(R, R)$ and $m:\left(\{0,1\},\left\{\theta_{L}, \theta_{H}\right\}\right) \rightarrow\{1,2,3,4\}$. The mapping $(q, l)$ prescribes a non-binding limit order $(q, l)(e, s)$ at the preopening stage on the basis of his endowment shock $e$ and private signal $s$. The mapping $m$ prescribes a market order $m(e, \theta)$ at the trading stage to execute one of the outsider's limit orders on the basis of his endowment shock $e$ and asset value $\theta$.

An outsider strategy is a pair of mappings $d:(R, R) \rightarrow\{0,1\}$ and $(\alpha, P):(R, R) \rightarrow R^{4} \times R^{4}$. The mapping $d$ prescribes an entry decision $d(q, l)$ conditional on the insider's non-binding limit order, where $d=1$ stands for entry while $d=0$ stands for no entry. The mapping $(\alpha, P)(q, l)$ prescribes the limit orders the outsider submits conditional on the insider's non-binding limit order. We use the convention that positive numbers of $q$ and $\alpha$ represent purchases. The conditional beliefs of the outsider are represented by a mapping that associates to each collection 
of limit orders $(q, l)$ a probability function $\operatorname{Pr}[\cdot \mid(q, l)]$ on $\{\tilde{e}, \tilde{\theta}\}$, where $\operatorname{Pr}[\tilde{e}=e, \tilde{\theta}=\theta \mid(q, l)]$ is the probability that the outsider attaches to $\{\tilde{e}=e, \tilde{\theta}=\theta\}$ given the insider's limit $\operatorname{order}(q, l)$.

To sum up, the trading stage is modeled as a principal-agent game with the outsider as principal and the insider as agent, and the preopening period is modeled as a round of pre-play communication where the agent can transmit information to the principal by submitting a nonbinding limit order.

\section{EQUILIBRIUM ANALYSIS}

We first consider a benchmark case with no information asymmetry. If the insider does not own the asset, i.e., $e=0$, no trade happens. However, if the insider owns the asset, i.e., $e=1$,

there are gains from trade. At the trading stage, the outsider proposes a price $P_{i}=\theta_{i}-\frac{1}{2} A \sigma^{2}$ to buy the asset from the insider when $\tilde{\theta}=\theta_{i}$, where $i=L, H$. Trading volume is always 1 . The insider can sell his total asset to the outsider regardless of the realization of the asset value $\tilde{\theta}$. This allocation allows an optimal transfer of risk from the risk-averse insider to the riskneutral outsider, and the pricing allows the outsider to extract all the gains from trade: she earns an expected profit equal to $\frac{1}{2} A \sigma^{2}$ while the insider has an expected utility equal to his outside option $\theta_{i}-\frac{1}{2} A \sigma^{2}$, where $i=L, H$. At the preopening stage, the outsider enters into the trading stage only if $\tilde{e}=1$ and $c \leq \frac{1}{2} A \sigma^{2}$.

We now turn to the more interesting case with information asymmetry. In this case, the insider has two trading motives: hedging and informed speculation, in line with Bhattacharya and Spiegel (1991). In this section, we will solve our model backward analyzing first the trading period, then the preopening period.

\section{(a) TRADING PERIOD}

At the trading stage, the outsider has already made her entry decision. The cost of market participation is thus a sunk cost. We therefore ignore it for now and will reintroduce it when we explicitly consider the entry decision and the participation constraint of the outsider at the preopening stage. Given that the outsider decided to enter the market, she has to choose a 
menu of limit order $(\alpha, P)$ to maximize her expected trading profits, given that the incentive and participation constraints of the insider are satisfied.

We denote $\alpha_{i}^{j}, P_{i}^{j}, U_{i}^{j}, V_{i}^{j}$ and $b_{i}^{j}$ as the trading volume, price, utility of the insider, the utility of the outsider and the outsider's belief at the trading stage on type $\left\{\tilde{e}=j, \tilde{\theta}=\theta_{i}\right\}$, where $j=0,1$ and $i=L, H$. By solving the trading game at the trading stage, we obtain the following result.

LEMMA 1 Denote $K=\frac{A \sigma^{2}}{\theta_{H}-\theta_{L}}$. For the case where $K \geq 1$, the equilibrium trading strategies and utilities of both the outsider and the insider in the trading stage are shown in Table 1. For the case where $K<1$, the results are in Table 2.

[Table 1 here]

[Table 2 here]

The coefficient $K$ represents the important risk-sharing benefits, measured by $A \sigma^{2}$, relative to the adverse selection risk, measured by the difference $\theta_{H}-\theta_{L}$. Tables 1 and 2 characterize the second best equilibrium and show how the outsider's order placement strategy, including prices and volumes, as well as how both agents' utilities are affected by adverse selection.

In Table 1 , we consider the case where $K \geq 1$, i.e., $A \sigma^{2} \geq \theta_{H}-\theta_{L}$. In this case, the insider without the asset will choose to stay out of the market rather than mimic the one with the asset. The limit orders proposed by the outsider for the insider without the asset always specify 0 trading volume. Both the insider and the outsider get their outside option values.

The limit orders for the insider with the asset, however, depends on the outsider's belief $\frac{b_{L}^{1}}{b_{H}^{1}}$, i.e., the likelihood of meeting type $\theta_{L}$ asset relative to type $\theta_{H}$ asset. There is a trade-off between efficiency and informational rent. To ensure that the insider with low quality asset $\theta_{L}$ will not mimic the one with high quality asset $\theta_{H}$, the insider with asset $\theta_{L}$ must obtain an informational rent, which is an increasing function of the trading volume of type $\theta_{H}\left(\alpha_{H}^{1}\right)$. Thus, a decrease in $\alpha_{H}^{1}$ will reduce the informational rent if the insider owns asset $\theta_{L}$, but it will simultaneously reduce the efficiency gain of risk sharing if the insider owns asset $\theta_{H}$. In this case, the trade-off 
between the informational cost and the risk-sharing efficiency depends on the outsider's belief $\frac{b_{L}^{1}}{b_{H}^{1}}$.

If the outsider believes that it is more likely to meet the insider with asset $\theta_{L}$, she cares more about the informational cost than the efficiency gain, thus $\alpha_{H}^{1}$ decreases with $\frac{b_{L}^{1}}{b_{H}^{1}}$. Actually, if $\frac{b_{L}^{1}}{b_{H}^{1}}$ is sufficiently large, i.e., $\frac{b_{L}^{1}}{b_{H}^{1}} \geq K$, the outsider will shut down the trading with the insider holding asset $\theta_{H}\left(\alpha_{H}^{1}=0\right)$. If the asset value $\tilde{\theta}$ turns out to be $\theta_{L}$, the insider sells the total asset to the outsider and obtains his outside option value plus informational rent $\alpha_{H}^{1}\left(\theta_{H}-\theta_{L}\right)$. The outsider gets a revenue equal to total efficiency gain of risk sharing $\frac{1}{2} A \sigma^{2}$ minus the informational rent paid to the insider $\alpha_{H}^{1}\left(\theta_{H}-\theta_{L}\right)$. If the asset value $\tilde{\theta}$ turns out to be $\theta_{H}$, the insider sells part or none of the asset to the outsider and always gets his outside option value. The outsider obtains a revenue equal to partial efficiency gain from risk sharing $\frac{1}{2} A \sigma^{2}\left(1-\left(1-\alpha_{H}^{1}\right)^{2}\right)$, which is 0 when $\alpha_{H}^{1}=0$.

In Table 2, we consider the case where $K<1$, i.e., $A \sigma^{2}<\theta_{H}-\theta_{L}$. In this case, the insider without the asset may want to mimic the one with the asset. When $\frac{b_{L}^{1}}{b_{H}^{1}}$ is sufficiently low, i.e., $\frac{b_{L}^{1}}{b_{H}^{1}}<K(1-K)$, the informational rent to the insider holding the type $\theta_{L}$ asset is very large. In this case, the insider without the asset but observing the asset value $\theta_{L}$ wants to pretend to have the liquidity needs and trade with the outsider to get the informational rent but a cost of bearing risk. In this case, on the one hand, the outsider should reduce the trading volume for the insider holding the type $\theta_{H}$ asset to reduce the informational rent. On the other hand, the outsider can increase the trading volume for the insider holding type $\theta_{L}$ asset beyond 1 to increase the cost of risk bearing for the insider without the asset. When the outsider believes that the probability to meet the insider without the asset but observing $\theta_{L}$ is sufficiently large, i.e., $\frac{b_{L}^{0}}{b_{L}^{1}}>\frac{1}{K+\frac{b_{L}^{1}}{b_{H}^{1}} \frac{1}{K}}-1$, she wants to distort the trading volume $\alpha_{L}^{1}$ and $\alpha_{H}^{1}$ for the insider with the asset further to shut down the participation of the insider without the asset. For the case where $\frac{b_{L}^{1}}{b_{H}^{1}}$ is large, i.e., $\frac{b_{L}^{1}}{b_{H}^{1}} \geq K(1-K)$, we return to the case where the insider without the asset always chooses to stay out of the market. We will get exactly the same results as in Table 1 . The utilities of the insider and the outsider are also displayed in the table. 
In summary, in the case where $K \geq 1$, if the insider does not own the asset, the outsider will not trade with the insider and no risk sharing is needed; if the insider owns the asset, the outsider buys all the endowment and the allocation of risk is optimal only when the asset is of low quality. However, when the asset is of high quality, the trading volume is lower than the optimal risk sharing level 1 to ensure incentive compatibility. In the case where $K<1$, if the insider does not own the asset, overtrading might exist since the insider without the asset may mimic the one with the asset; if the insider owns the asset, undertrading always happens and risk sharing is lower than the optimal level when the asset is of high quality. When the asset is of low quality, overtrading might happen, in which case the allocation of risk is not optimal either.

In addition, we can see that the outsider's beliefs concerning the types of insiders, especially

$\frac{b_{L}^{1}}{b_{H}^{1}}$, have a crucial impact on the limit orders she proposes to the insider at the trading stage. In the following, we will study whether the insider can transmit his private information on liquidity needs and (or) asset values to the outsider at the preopening stage in order to influence her belief, and thereby influence her order placement strategy at the trading stage.

\section{(b) PREOPENING PERIOD}

For the analysis of the preopening stage, the strategy profiles at the trading stage are omitted since they correspond to the equilibrium situation. There are fifteen pure strategy profiles that are candidates for equilibrium at the preopening stage. We classify these strategy profiles into two categories:

i) Category I strategy profiles: the insider chooses to preannounce the same non-binding limit order $\left(q_{1}, l_{1}\right)$ for $\left(\tilde{e}=1, \tilde{s}=\theta_{H}\right)$ and $\left(\tilde{e}=1, \tilde{s}=\theta_{L}\right)$. That is, the insider owning the asset chooses to send the same message to the outsider regardless of his private signal on asset value. The outsider updates her beliefs over $\tilde{e}$ and $\tilde{\theta}$ based on the strategy and the non-binding limit order the insider takes, and then determines her entry decision $\mathrm{d}$ and subsequent trading strategies. In Table 3, we list the details of the five category I strategies, i.e., strategies 1 to 5, and the updated outsider's beliefs over four types. 
ii) Category II strategy profiles: the insider chooses to preannounce two different non-binding limit orders $\left(q_{1}, l_{1}\right)$ and $\left(q_{2}, l_{2}\right)$ for $\left(\tilde{e}=1, \tilde{s}=\theta_{H}\right)$ and $\left(\tilde{e}=1, \tilde{s}=\theta_{L}\right)$, respectively. That is, the insider owning the asset chooses to send different messages to the outsider conditional on his private signal on asset value. The outsider updates her beliefs over $\tilde{e}$ and $\tilde{\theta}$ based on the strategy and the non-binding limit order the insider takes, and then determines her entry decision $\mathrm{d}$ and subsequent trading strategies. In Table 4, we list the details of the ten category II strategies, i.e., strategies 6 to 15, and the updated outsider's beliefs over four types.

[Table 3 here]

[Table 4 here]

To complete the characterization of the perfect Bayesian equilibrium, we specify the following out-of-equilibrium beliefs: if the outsider observes an action that is not part of the equilibrium path, the outsider makes entry and trading decisions based on her prior belief on liquidity needs and asset values.

The main idea behind the above classification is the following: the main agency problem in our framework is that the insider with the asset observing a low quality signal has incentives to pretend to receive a high quality signal. By doing so, the insider wants to reduce the outsider's belief on the likelihood of a low quality asset relative to a high quality one $\left(\frac{b_{L}^{1}}{b_{H}^{1}}\right)$ and increase his own informational rent at the trading stage. For category I strategies, the insider with the asset always sends the same message to the outsider regardless of his private signal. For these strategies, this agency problem is not an issue. However, for category II strategies, the insider with the asset sends different messages to the outsider conditional on his private signal. The main objective is to find the conditions under which the insider with the asset pretending to receive a high quality signal is prevented.

Denote $V\left(b_{L}^{0}, b_{H}^{0}, b_{L}^{1}, b_{H}^{1}\right)$ as the expected utility of the outsider at the preopening stage given no entry cost and her belief $b_{i}^{j}$ over $\left(\tilde{e}=j, \tilde{\theta}=\theta_{i}\right)$, where $j=0,1$ and $i=L, H$. Please see the detailed function of $V\left(b_{L}^{0}, b_{H}^{0}, b_{L}^{1}, b_{H}^{1}\right)$ in Appendix B. Denote $V_{i, j}$ as the expected utility of the outsider without entry cost conditional on message $\left(q_{i}, l_{i}\right)$ and the insider's strategy $j$ at the preopening stage, where $i=1, \ldots, 4$ and $j=1, \ldots, 15$, i.e., $V_{i, j}=V\left(b_{L}^{0}, b_{H}^{0}, b_{L}^{1}, b_{H}^{1} \mid\left(q_{i}, l_{i}\right)\right.$, strategy $\left.\mathrm{j}\right)$, 
and $V_{0}$ as the expected utility of the outsider without entry cost with her prior beliefs over $(\tilde{e}, \tilde{\theta})$, i.e., $V_{0}=V\left(\frac{1}{2}(1-\lambda), \frac{1}{2}(1-\lambda), \frac{1}{2} \lambda, \frac{1}{2} \lambda\right)$.

For category I strategies, the insider with the asset chooses to send the same message to the outsider at the preopening stage regardless of his private signal on asset value. This type of strategies precludes the insider with the asset from pretending to receive a high quality signal. It thus yields the following result:

PROPOSITION 1 A category I strategy is always an equilibrium.

We compare the category I strategies and obtain the following result. In this paper, we call a strategy dominates if both the outsider and the insider earn higher utility or at least as high as any other strategy in the comparison.

PROPOSITION 2 Strategy 1 , where the insider preannounces $\left(q_{1}, l_{1}\right)$ if he owns the asset and $\left(q_{2}, l_{2}\right)$ if he does not, dominates other category I strategies.

Proposition 2 implies that, among category I strategies, both the insider and the outsider are better off by communicating endowment shocks at the preopening stage (Strategy 2 is equivalent to strategy 1 since communicating private signals in case of no liquidity need does not add value). Through this communication, the outsider provides liquidity only when the liquidity need is preannounced by the insider. The outsider benefits from this communication by saving her entry cost in case of no liquidity needs. The insider also benefits because this communication allows more entry of the outsider when the participation cost is high and reduces the probability of market breakdown.

We next characterize whether and when a category II strategy profile can be an equilibrium.

PROPOSITION 3 A category II strategy $j$, where $j=6, \ldots, 15$, is an equilibrium under the following four scenarios: $i$ ) if $K \leq \frac{1-p}{p}$; ii) if $\frac{1-p}{p}<K \leq 1$ and $c>V_{1, j}$; iii) if $1<K \leq \frac{p}{1-p}$ and $c>\max \left\{V_{0}, V_{1, j}\right\}$; and iv) if $K>\frac{p}{1-p}$ and $c>\max \left\{V_{0}, V_{1, j}, V_{2, j}\right\}$.

For category II strategies, the insider with the asset sends different messages conditional on his private signal on asset value. Thus, the insider with the asset observing a low quality signal 
has incentives to mimic a high quality signal to reduce the outsider's belief $\frac{b_{L}^{1}}{b_{H}^{1}}$ and increase his informational rent at the trading stage.

Proposition 3 argues that a category II strategy can be an equilibrium, but its feasibility depends on the magnitude of $K$. First, if $K$ is sufficiently small, i.e., $K \leq \frac{1-p}{p}$, regardless of the insider's reports at the preopening stage, the outsider's belief $\frac{b_{L}^{1}}{b_{H}^{1}}$ is always larger than the threshold $K$. In this case, the trading profiles at the trading stage are as Scenario 4 in Table 2 and the insider always obtains outside option value. Thus, the insider with the asset has no incentive to lie about his private signal on asset value.

Second, if $\frac{1-p}{p}<K \leq 1$, the insider with the asset observing signal $\theta_{L}$ has incentives to send message $\left(q_{1}, l_{1}\right)$ to pretend to receive signal $\theta_{H}$, since by doing this he can get more informational rent at the trading stage. The outsider can punish the lying behavior of the insider through no entry conditional on message $\left(q_{1}, l_{1}\right)$. The condition $c>V_{1, j}$ ensures that this punishment is credible. In this parameter range, the insider has no incentive to switch to off-equilibrium strategies either, since he gets no informational rent by doing so.

Third, if $1<K \leq \frac{p}{1-p}$, the mechanism is similar to the second scenario with one difference that $c>\max \left\{V_{0}, V_{1, j}\right\}$, where the condition $c>\max \left\{V_{0}, V_{1, j}\right\}$ ensures that the outsider chooses no entry given message $\left(q_{1}, l_{1}\right)$ or her prior beliefs. Thus, the above condition prevents the insider from pretending to receive a high quality signal or reporting other off-equilibrium messages at the preopening stage.

Fourth, if $K$ is sufficiently large, i.e., $K>\frac{p}{1-p}$, the condition $c>\max \left\{V_{0}, V_{1, j}, V_{2, j}\right\}$ ensures that the outsider would never enter into the trading stage regardless of the insider's reports at the preopening stage. Thus, the insider has no incentives to lie on his private signals. This parameter range is less interesting since no trading occurs.

In our framework, the outsider must pay a cost $c$ to enter into the trading stage. One could think that the introduction of the entry cost is a bad thing for trading. However, we find that the introduction of the entry cost is sometimes a good thing for information transmission at the preopening stage. By comparing with the case without entry cost, we obtain an interesting result as follows. 
COROLLARY 1 With an entry cost $c$, the contingent entry decision made by the outsider based on the information at the preopening stage can work as a mechanism to punish the lying behavior of the insider and make the information transmission on private signals be feasible in a wider parameter range. In order to make the punishment credible, the entry cost must be sufficiently high.

Without an entry cost, the outsider always enters into the trading stage regardless of the insider's report. In this case, when the insider owns the asset, sending different messages conditional on private signals cannot be an equilibrium when $K$ is relatively large. However, with an entry cost, the outsider not only designs her trading profiles but also makes her entry decision contingent on the information she receives from the insider at the preopening stage. This contingent entry decision can work as a mechanism to punish the lying behavior of the insider. The insider with the asset observing signal $\theta_{L}$ has an incentive to mimic $\theta_{H}$, while the contingent no entry decision of the outsider works as a punishment mechanism to ensure that the insider has no incentive to lie. In this case, the entry cost makes the transmission on private signals to be feasible in a wider parameter range. But the existence of the entry cost does not guarantee the credibility of the punishment. If the entry cost is lower than the outsider's expected utility, the outsider cannot promise to stay out of the market given message $\left(q_{1}, l_{1}\right)$ for signal $\theta_{H}$. Thus, to make the punishment promise credible, the entry cost must be sufficiently high.

Next, we compare the equilibria of category II strategies and obtain the result as follows.

\section{PROPOSITION 4}

- If $K \leq \frac{1-p}{p}$, strategy 6 , where the insider preannounces $\left(q_{1}, l_{1}\right)$ if he observes $\left(1, \theta_{H}\right)$, $\left(q_{2}, l_{2}\right)$ if he observes $\left(1, \theta_{L}\right)$, and $\left(q_{3}, l_{3}\right)$ if he observes $(\tilde{e}, \tilde{s}) \in\left\{\left(0, \theta_{H}\right),\left(0, \theta_{L}\right)\right\}$, dominates other category II strategies.

- If $\frac{1-p}{p}<K \leq \frac{p}{1-p}$, strategy 14 , where the insider preannounces $\left(q_{1}, l_{1}\right)$ if he observes $(\tilde{e}, \tilde{s}) \in\left\{\left(1, \theta_{H}\right),\left(0, \theta_{H}\right),\left(0, \theta_{L}\right)\right\}$ and $\left(q_{2}, l_{2}\right)$ if he observes $\left(1, \theta_{L}\right)$, dominates other category II strategies.

- If $K>\frac{p}{1-p}$, there is no trading in all category II equilibria. 
If $K \leq \frac{1-p}{p}$, any category II strategy is an equilibrium. Strategy 6 dominates because the outsider is better off by making entry and trading decisions contingent on the most precise information, while this would not hurt the insider since he always obtains the outside option value in equilibria in this parameter range (Strategy 7 is equivalent to strategy 6 since communicating private signals in case of no liquidity need does not add value.). If $\frac{1-p}{p}<K \leq \frac{p}{1-p}$, in all category II equilibria the outsider can enter into the trading stage only if she observes $\left(q_{2}, l_{2}\right)$ and stays out of the market otherwise. This no entry decision works as a punishment mechanism for the lying behavior of the insider. With strategy 14 , both the insider and the outsider benefit from perfectly coordinating the liquidity supply and demand given message $\left(q_{2}, l_{2}\right)$ since the insider communicates $\left(q_{2}, l_{2}\right)$ only when he observes $\left(\tilde{e}=1, \tilde{s}=\theta_{L}\right)$ without mixing with the no liquidity need types as some other category II strategies. Moreover, by sending the same preopening message $\left(q_{1}, l_{1}\right)$ for type $\left(\tilde{e}=1, \tilde{s}=\theta_{H}\right)$ and the other two types without liquidity shocks, the outsider's expected utility conditional on $\left(q_{1}, l_{1}\right)$ is the lowest and thus the punishment condition is easiest to be satisfied. If $K>\frac{p}{1-p}$, there is no trading in all Category II equilibria.

\section{(c) SELECTION OF EQUILIBRIUM}

In this subsection, we consider the selection of equilibrium. Since the insider is active at the preopening stage, we assume that he decides which equilibrium to play based on the following rule: at the preopening stage, the insider selects the equilibrium that maximizes his expected utility subject to the participation constraint of the outsider, and in the case where he obtains exactly the same utility at different equilibria, he chooses the one which maximizes the expected payoff of the outsider.

PROPOSITION 5 At the preopening stage,

- If $K \leq \frac{1-p}{p}$, the insider chooses strategy 6, i.e., preannouncing $\left(q_{1}, l_{1}\right)$ if he observes $\left(1, \theta_{H}\right),\left(q_{2}, l_{2}\right)$ if he observes $\left(1, \theta_{L}\right)$, and $\left(q_{3}, l_{3}\right)$ otherwise.

- If $\frac{1-p}{p}<K \leq \frac{p}{1-p}$, there exists $c^{\prime}>0$ such that the insider chooses strategy 1, i.e., preannouncing $\left(q_{1}, l_{1}\right)$ if he owns the asset and $\left(q_{2}, l_{2}\right)$ otherwise, when $c \in\left[0, c^{\prime}\right]$, and strat- 
egy 14 , i.e., preannouncing $\left(q_{2}, l_{2}\right)$ if he observes $\left(1, \theta_{L}\right)$, and $\left(q_{1}, l_{1}\right)$ otherwise, when $c \in\left(c^{\prime},+\infty\right)$.

- If $K>\frac{p}{1-p}$, the insider chooses strategy 1, i.e., preannouncing $\left(q_{1}, l_{1}\right)$ if he owns the asset and $\left(q_{2}, l_{2}\right)$ otherwise.

The exact value of $c^{\prime}$ is as equation (23) in Appendix G. The result of Proposition 5 is depicted in Figure 2.

[Figure 2 here]

The economic intuition is that if $K$ is large, i.e., the gains from trade $A \sigma^{2}$ is large or the adverse risk faced by the outsider is not a major concern with a small $\theta_{H}-\theta_{L}$, the insider and the outsider only communicate the liquidity needs, i.e., strategy 1 . However, if $K$ is small, i.e., the gains from trade $A \sigma^{2}$ is small and the adverse risk becomes a main issue with a large $\theta_{H}-\theta_{L}$, the insider with the asset prefers to fully communicate private signals, i.e., strategy 6 . With intermediate $K$, the equilibrium depends on the magnitude of the entry cost. With a larger $c$, the outsider is more able to use the contingent entry decision to punish the lying behavior of the insider by staying out of the market. In this case, partially communicating private signals for the insider with the asset becomes a more feasible tool at the preopening stage. The result that the insider is voluntarily revealing some information during the preopening period to reduce adverse selection costs for the outsider may appear counterintuitive. This is because, conditional on trading, the insider would prefer having such an advantage. However, given that the outsider may not participate in the market because of the adverse selection cost and the cost of market participation, the insider is better off preannouncing his advantage to increase the likelihood of trading.

\section{INFORMATION TRANSMISSION, LIQUIDITY FORMATION AND SOCIAL WELFARE}

In this section, we study how the existence of a preopening period, especially the information transmission on liquidity needs and/or private signals at this period, affects liquidity formation and social welfare. Specifically, we compare strategy 1, 6 or 14 with the case of no preopening 
period since these three strategies dominate other strategies in equilibrium and are selected by the insider at the preopening stage.

The following proposition illustrates how the communication of liquidity needs at the preopening stage affects liquidity formation.

PROPOSITION 6 Compared with the case of no preopening period, communication of liquidity needs at the preopening stage, i.e., strategy 1, allows better coordination of the demand and supply of liquidity, and is able to avoid market breakdown when $c \in\left(V_{0}, V_{1,1}\right]$.

The outsider provides liquidity only if the liquidity need is preannounced by the insider, and stays out of the market otherwise. The communication of liquidity needs helps save the outsider's entry cost and coordinate the demand and the supply of liquidity. The outsider is better off and would like to enter more into the trading stage, thus reducing the occurrence of market breakdown. When $c \in\left(V_{0}, V_{1,1}\right]$, the outsider chooses to stay out of the market without a preopening period, however trading occurs if the liquidity need is preannounced by the insider at the preopening stage.

Next we analyze the impact on market liquidity formation of communication of private signals by the insider with the asset through strategy 6 or 14 .

PROPOSITION 7 Compared with the case of no preopening period, strategy $j$, where $j=$ 6,14, always improves liquidity provision through fully or partially communicating private signals, except on the occasion $V_{1, j}<V_{0}$, where the outsider provides less liquidity when $c \in\left(V_{1, j}, V_{0}\right]$.

Proposition 7 tells us that most of the time, communicating private signals in strategy 6 or 14 can help reduce market breakdown phenomena that would occur in the absence of a preopening period and improve liquidity provision. Such an increase is however not guaranteed because the outsider's entry decision is less in phase with liquidity needs. In the case where $V_{1, j}<V_{0}$ and $c \in\left(V_{1, j}, V_{0}\right]$, without preopening stage, the outsider always enters into the trading game. However, through communicating private signals at the preopening stage, the outsider enters only if the insider with the asset observing a low quality signal is preannounced to reduce the adverse selection risk she faces. In this case, the outsider provides less liquidity. 
In the following, we turn to analyze how these three strategies affect the social welfare.

PROPOSITION 8 Compared with the case of no preopening period, the communication of liquidity needs and/or private signals at the preopening stage through strategies 1,6 and 14 always improves social welfare.

Communicating liquidity needs better coordinates the supply and demand of liquidity and preannouncing private signals on asset value reduces the adverse selection risk faced by the outsider. In other words, the communication of liquidity needs and/or private signals allows the outsider to make more efficient entry and trading decisions based on more precise information. Thus, the outsider is better off. The insider is not worse off, otherwise he can switch to report off-equilibrium messages and the outsider will decide entry and trading strategies based her prior belief, the possibility of which has been ruled out when constructing the equilibrium.

\section{CONCLUSION}

This paper studies the role of preopening periods in financial markets. We propose a theoretical model where a preopening period is instrumental in the liquidity formation process. In our setting, liquidity is latent because of the cost of market participation and because of information asymmetries. At equilibrium, risk-averse insiders use the preopening period to communicate liquidity needs and/or their private information concerning asset valuation. This communication mitigates the influence of market imperfections. Welfare can be enhanced owing to the savings on the cost of market participation and a reduction in the adverse selection risk borne by liquidity providers. In addition, the introduction of a preopening period is expected to reduce the likelihood of market breakdowns.

This paper has implications for portfolio management. It suggests that preopening periods can be used to attract latent liquidity. As a result, the actual market liquidity can be higher than what is indicated by the average state of the order book. Indeed, trading sessions where preannouncement has been made during the preopening period display a high liquidity. On the contrary, trading sessions where no preannouncement has occurred display a low liquidity. Overall, the time series averages of liquidity measures do not reflect the latent liquidity and thus underestimate the quality of the market. Portfolio managers can thus benefit from realizing 
that liquidity is endogenous and responds positively to the implementation of trading strategies based on preannouncements. This is in line with the empirical findings of Dia and Pouget (2011).

This paper also has implications for the design of financial markets. It shows that introducing a preopening period may trigger welfare improvements when there is a cost of market participation. Market organizers may thus have an interest in providing traders with pre-trade communication platforms such as preopening periods as a way to disseminate information regarding both liquidity needs and asset valuation.

\section{ACKNOWLEDGEMENTS}

We thank the anonymous referee and Ian Martin, the Editor for insightful comments. We have also benefited from comments by Elena Asparouhova, Shmuel Baruch, Hank Bessembinder, Bruno Biais, Fany Declerck, Thierry Foucault, Bruce Lehmman, Yee Cheng Loon, Venky Panchapagesan, Anand Venkateswaran, Pierre-Olivier Weil and by seminar participants at the University of Utah, the NBER market microstructure conference in Boston, the conference on New Financial Market Structures in HEC-Montreal, and the Financial Market Liquidity Conference in Budapest. We especially thank Magueye Dia for his insights and his participation on an early version of this paper.

\section{APPENDIX A: PROOF OF LEMMA 1}

Because the utility function of the insider is a CARA utility function and the distribution of $\tilde{v}$ conditional on $\tilde{\theta}=\theta_{i}$ is a normal random variable with mean $\theta_{i}$ and variance $\sigma^{2}$, the incentive compatibility constraints ensuring that the insider observing $\tilde{\theta}=\theta_{L}$ has no incentive to lie about his endowment shock are as follows:

$$
\alpha_{L}^{0} P_{L}^{0}-\alpha_{L}^{0} \theta_{L}-\frac{1}{2} A \sigma^{2}\left(-\alpha_{L}^{0}\right)^{2} \geq \alpha_{L}^{1} P_{L}^{1}-\alpha_{L}^{1} \theta_{L}-\frac{1}{2} A \sigma^{2}\left(-\alpha_{L}^{1}\right)^{2}
$$

and

$$
\alpha_{L}^{1} P_{L}^{1}+\left(1-\alpha_{L}^{1}\right) \theta_{L}-\frac{1}{2} A \sigma^{2}\left(1-\alpha_{L}^{1}\right)^{2} \geq \alpha_{L}^{0} P_{L}^{0}+\left(1-\alpha_{L}^{0}\right) \theta_{L}-\frac{1}{2} A \sigma^{2}\left(1-\alpha_{L}^{0}\right)^{2}
$$


where condition (2) implies that given observing $\tilde{\theta}=\theta_{L}$, the insider without the asset does not want to mimic the one with the asset, and condition (3) indicates that the insider has the asset does not want to pretend that he does not.

Similarly, we obtain the incentive compatibility constraints which guarantee that the insider observing $\tilde{\theta}=\theta_{H}$ has no incentive to lie about his endowment shock:

$$
\alpha_{H}^{0} P_{H}^{0}-\alpha_{H}^{0} \theta_{H}-\frac{1}{2} A \sigma^{2}\left(-\alpha_{H}^{0}\right)^{2} \geq \alpha_{H}^{1} P_{H}^{1}-\alpha_{H}^{1} \theta_{H}-\frac{1}{2} A \sigma^{2}\left(-\alpha_{H}^{1}\right)^{2}
$$

and

$$
\alpha_{H}^{1} P_{H}^{1}+\left(1-\alpha_{H}^{1}\right) \theta_{H}-\frac{1}{2} A \sigma^{2}\left(1-\alpha_{H}^{1}\right)^{2} \geq \alpha_{H}^{0} P_{H}^{0}+\left(1-\alpha_{H}^{0}\right) \theta_{H}-\frac{1}{2} A \sigma^{2}\left(1-\alpha_{H}^{0}\right)^{2}
$$

In addition, we also need to make sure that the insider does not want to lie about his private information of asset value. The incentive compatibility constraints ensuring that the insider without the asset does not lie about his observation of $\tilde{\theta}$ are

$$
\alpha_{L}^{0} P_{L}^{0}-\alpha_{L}^{0} \theta_{L}-\frac{1}{2} A \sigma^{2}\left(-\alpha_{L}^{0}\right)^{2} \geq \alpha_{H}^{0} P_{H}^{0}-\alpha_{H}^{0} \theta_{L}-\frac{1}{2} A \sigma^{2}\left(-\alpha_{H}^{0}\right)^{2}
$$

and

$$
\alpha_{H}^{0} P_{H}^{0}-\alpha_{H}^{0} \theta_{H}-\frac{1}{2} A \sigma^{2}\left(-\alpha_{H}^{0}\right)^{2} \geq \alpha_{L}^{0} P_{L}^{0}-\alpha_{L}^{0} \theta_{H}-\frac{1}{2} A \sigma^{2}\left(-\alpha_{L}^{0}\right)^{2}
$$

where condition (6) guarantees that given no endowment shock, the insider observing $\theta_{L}$ does not want to mimic $\theta_{H}$, and condition (7) ensures that the insider observing $\theta_{H}$ does not pretend to observe $\theta_{L}$.

Similarly, the incentive constraints where the insider with the asset does not lie about his observation on $\tilde{\theta}$ are

$$
\alpha_{L}^{1} P_{L}^{1}+\left(1-\alpha_{L}^{1}\right) \theta_{L}-\frac{1}{2} A \sigma^{2}\left(1-\alpha_{L}^{1}\right)^{2} \geq \alpha_{H}^{1} P_{H}^{1}+\left(1-\alpha_{H}^{1}\right) \theta_{L}-\frac{1}{2} A \sigma^{2}\left(1-\alpha_{H}^{1}\right)^{2}
$$


and

(9) $\alpha_{H}^{1} P_{H}^{1}+\left(1-\alpha_{H}^{1}\right) \theta_{H}-\frac{1}{2} A \sigma^{2}\left(1-\alpha_{H}^{1}\right)^{2} \geq \alpha_{L}^{1} P_{L}^{1}+\left(1-\alpha_{L}^{1}\right) \theta_{H}-\frac{1}{2} A \sigma^{2}\left(1-\alpha_{L}^{1}\right)^{2}$.

In addition to the incentive compatibility constraints, we also need to consider participation constraints of the insider with four different types.

(10) $\alpha_{L}^{0} P_{L}^{0}-\alpha_{L}^{0} \theta_{L}-\frac{1}{2} A \sigma^{2}\left(-\alpha_{L}^{0}\right)^{2} \geq 0$

(11) $\alpha_{H}^{0} P_{H}^{0}-\alpha_{H}^{0} \theta_{H}-\frac{1}{2} A \sigma^{2}\left(-\alpha_{H}^{0}\right)^{2} \geq 0$,

(12) $\alpha_{L}^{1} P_{L}^{1}+\left(1-\alpha_{L}^{1}\right) \theta_{L}-\frac{1}{2} A \sigma^{2}\left(1-\alpha_{L}^{1}\right)^{2} \geq \theta_{L}-\frac{1}{2} A \sigma^{2}$

and

(13) $\alpha_{H}^{1} P_{H}^{1}+\left(1-\alpha_{H}^{1}\right) \theta_{H}-\frac{1}{2} A \sigma^{2}\left(1-\alpha_{H}^{1}\right)^{2} \geq \theta_{H}-\frac{1}{2} A \sigma^{2}$.

Conditions (10), (11), (12), and (13) ensure that the insider will at least get his outside option value.

The outsider proposes a menu of limit orders to maximize his own profit subject to all the incentive and participation constraints. Thus the program of the outsider is

$$
\max _{\alpha_{i}^{j}, P_{i}^{j}} b_{L}^{0} \alpha_{L}^{0}\left(\theta_{L}-P_{L}^{0}\right)+b_{H}^{0} \alpha_{H}^{0}\left(\theta_{H}-P_{H}^{0}\right)+b_{L}^{1} \alpha_{L}^{1}\left(\theta_{L}-P_{L}^{1}\right)+b_{H}^{1} \alpha_{H}^{1}\left(\theta_{H}-P_{H}^{1}\right)
$$

s.t. Conditions (2) - (13). 


\section{Denote}

$$
\begin{aligned}
U_{L}^{0} & =\alpha_{L}^{0} P_{L}^{0}-\alpha_{L}^{0} \theta_{L}-\frac{1}{2} A \sigma^{2}\left(-\alpha_{L}^{0}\right)^{2} \\
U_{H}^{0} & =\alpha_{H}^{0} P_{H}^{0}-\alpha_{H}^{0} \theta_{H}-\frac{1}{2} A \sigma^{2}\left(-\alpha_{H}^{0}\right)^{2} \\
U_{L}^{1} & =\alpha_{L}^{1} P_{L}^{1}+\left(1-\alpha_{L}^{1}\right) \theta_{L}-\frac{1}{2} A \sigma^{2}\left(1-\alpha_{L}^{1}\right)^{2} \\
U_{H}^{1} & =\alpha_{H}^{1} P_{H}^{1}+\left(1-\alpha_{H}^{1}\right) \theta_{H}-\frac{1}{2} A \sigma^{2}\left(1-\alpha_{H}^{1}\right)^{2},
\end{aligned}
$$

Thus, Program (14) can be rewritten as

$$
\begin{array}{ll}
\max _{\left(\alpha_{i}^{j}, U_{i}^{j}\right)_{j=0,1 ; i=L, H}} & b_{L}^{1} \theta_{L}+b_{H}^{1} \theta_{H}-\frac{1}{2} A \sigma^{2}\left[b_{L}^{0}\left(\alpha_{L}^{0}\right)^{2}+b_{H}^{0}\left(\alpha_{H}^{0}\right)^{2}+b_{L}^{1}\left(1-\alpha_{L}^{1}\right)^{2}+b_{H}^{1}\left(1-\alpha_{H}^{1}\right)^{2}\right] \\
& -\left[b_{L}^{0} U_{L}^{0}+b_{H}^{0} U_{H}^{0}+b_{L}^{1} U_{L}^{1}+b_{H}^{1} U_{H}^{1}\right] \\
& U_{L}^{0} \geq U_{L}^{1}-\theta_{L}+\frac{1}{2} A \sigma^{2}\left(1-2 \alpha_{L}^{1}\right) \quad\left(I C_{1}\right) \\
& U_{L}^{1} \geq U_{L}^{0}+\theta_{L}-\frac{1}{2} A \sigma^{2}\left(1-2 \alpha_{L}^{0}\right) \quad\left(I C_{2}\right) \\
& U_{H}^{0} \geq U_{H}^{1}-\theta_{H}+\frac{1}{2} A \sigma^{2}\left(1-2 \alpha_{H}^{1}\right) \quad\left(I C_{3}\right) \\
& U_{H}^{1} \geq U_{H}^{0}+\theta_{H}-\frac{1}{2} A \sigma^{2}\left(1-2 \alpha_{H}^{0}\right) \quad\left(I C_{4}\right) \\
U_{L}^{0} & \geq U_{H}^{0}+\alpha_{H}^{0}\left(\theta_{H}-\theta_{L}\right) \quad\left(I C_{5}\right) \\
U_{H}^{0} & \geq U_{L}^{0}-\alpha_{L}^{0}\left(\theta_{H}-\theta_{L}\right) \quad\left(I C_{6}\right) \\
& U_{L}^{1} \geq U_{H}^{1}-\left(1-\alpha_{H}^{1}\right)\left(\theta_{H}-\theta_{L}\right) \quad\left(I C_{7}\right) \\
& U_{H}^{1} \geq U_{L}^{1}+\left(1-\alpha_{L}^{1}\right)\left(\theta_{H}-\theta_{L}\right) \quad\left(I C_{8}\right) \\
& U_{L}^{0} \geq 0\left(P C_{1}\right), U_{H}^{0} \geq 0\left(P C_{2}\right), U_{L}^{1} \geq \theta_{L}-\frac{1}{2} A \sigma^{2}\left(P C_{3}\right), U_{H}^{1} \geq \theta_{H}-\frac{1}{2} A \sigma^{2}\left(P C_{4}\right) .
\end{array}
$$

First, we obtain the first-best case by maximizing the program subject to the participation constraints. It yields that $U_{L}^{0}=U_{H}^{0}=0, U_{L}^{1}=\theta_{L}-\frac{1}{2} A \sigma^{2}, U_{H}^{1}=\theta_{H}-\frac{1}{2} A \sigma^{2}, \alpha_{L}^{0}=\alpha_{H}^{0}=0$ and $\alpha_{L}^{1}=\alpha_{H}^{1}=1$. Check whether the first-best solutions satisfy the IC constraints. By plugging the solutions into the constraints, we find that $I C_{7}$ constraint does not hold. In other words, given the first-best results, the insider holding low quality asset $\theta_{L}$ would like to pretend to hold high quality asset $\theta_{H}$.

In this case, we guess that $I C_{7}$ should be binding, i.e., $U_{L}^{1}=U_{H}^{1}-\left(1-\alpha_{H}^{1}\right)\left(\theta_{H}-\theta_{L}\right)$. Given $I C_{7}$ is binding, $P C_{3}$ cannot be binding. In this case, we maximize the expected utility of the 
outsider subject to $I C_{7}, P C_{1}, P C_{2}$ and $P C_{4}$, while ignoring other IC and PC constraints (we will check whether other constraints hold afterwards).

The solutions are: $U_{L}^{0}=U_{H}^{0}=0, U_{L}^{1}=\theta_{L}-\frac{1}{2} A \sigma^{2}+\alpha_{H}^{1}\left(\theta_{H}-\theta_{L}\right), U_{H}^{1}=\theta_{H}-\frac{1}{2} A \sigma^{2}, \alpha_{L}^{0}=$ $\alpha_{H}^{0}=0, \alpha_{L}^{1}=1$ and $\alpha_{H}^{1}=1-\frac{b_{L}^{1}}{b_{H}^{1}} \frac{\theta_{H}-\theta_{L}}{A \sigma^{2}}$. Given the solutions, we find all PCs and ICs are satisfied if $0 \leq \alpha_{H}^{1} \leq \frac{A \sigma^{2}}{\theta_{H}-\theta_{L}}$. In other words, the solutions satisfy all the constraints if $K(1-K) \leq \frac{b_{L}^{1}}{b_{H}^{1}} \leq K$. We consider two different cases where $K<1$ and $K \geq 1$.

\section{CASE: $K<1$}

In this case, $K(1-K)>0$.

Thus, if $K(1-K) \leq \frac{b_{L}^{1}}{b_{H}^{1}} \leq K$, we obtain that $U_{L}^{0}=U_{H}^{0}=0, U_{L}^{1}=\theta_{L}-\frac{1}{2} A \sigma^{2}+\alpha_{H}^{1}\left(\theta_{H}-\theta_{L}\right)$, $U_{H}^{1}=\theta_{H}-\frac{1}{2} A \sigma^{2}, \alpha_{L}^{0}=\alpha_{H}^{0}=0, \alpha_{L}^{1}=1$ and $\alpha_{H}^{1}=1-\frac{b_{L}^{1}}{b_{H}^{1}} \frac{1}{K}$. In other words, we obtain Scenario 3 in Table 2.

However, if $\frac{b_{L}^{1}}{b_{H}^{1}}>K, I C_{2}, I C_{3}$ and $P C_{3}$ are not satisfied, and if $0 \leq \frac{b_{L}^{1}}{b_{H}^{1}}<K(1-K), I C_{1}$ is not satisfied.

In the case where $\frac{b_{L}^{1}}{b_{H}^{1}}>K$, the outsider believes that the probability to meet an insider who holds low quality asset is sufficiently high. In this case, we guess that she would like to shut down the trading with the insider holding high quality asset to reduce the informational rent to the insider who holds the low quality asset. Thus, we guess $I C_{7}, P C_{1}, P C_{2}, P C_{3}$ and $P C_{4}$ should be binding. By solving the program, we obtain that $U_{L}^{0}=U_{H}^{0}=0, U_{L}^{1}=\theta_{L}-\frac{1}{2} A \sigma^{2}$, $U_{H}^{1}=\theta_{H}-\frac{1}{2} A \sigma^{2}, \alpha_{L}^{0}=\alpha_{H}^{0}=0, \alpha_{L}^{1}=1$ and $\alpha_{H}^{1}=0$. Given the results, all constraints are satisfied. Thus, we obtain Scenario 4 in Table 2.

In the case where $0 \leq \frac{b_{L}^{1}}{b_{H}^{1}}<K(1-K)$, the outsider investor believes that the probability to meet an insider who holds low quality is very low, so the informational rent gained by the low quality asset is very high. In this case, the outsider who observes $\theta_{L}$ but without any endowment would like to mimic the one who holds the asset. Thus, we guess that both $I C_{7}$ and $I C_{1}$ should be binding. Given $I C_{1}$ binding, $P C_{1}$ cannot be binding. Thus, we maximize the program subject to $I C_{1}, I C_{7}, P C_{2}$ and $P C_{4}$.

The solutions are $U_{L}^{0}=\alpha_{H}^{1}\left(\theta_{H}-\theta_{L}\right)-A \sigma^{2} \alpha_{L}^{1}, U_{H}^{0}=0, U_{L}^{1}=\theta_{L}-\frac{1}{2} A \sigma^{2}+\alpha_{H}^{1}\left(\theta_{H}-\theta_{L}\right)$, $U_{H}^{1}=\theta_{H}-\frac{1}{2} A \sigma^{2}, \alpha_{L}^{0}=0, \alpha_{H}^{0}=0, \alpha_{L}^{1}=1+\frac{b_{L}^{0}}{b_{L}^{1}}$ and $\alpha_{H}^{1}=1-\frac{b_{L}^{0}+b_{L}^{1}}{b_{H}^{1}} \frac{1}{K}$. We find that $I C_{6}$ does not hold given the solutions. Thus, we further guess $I C_{7}, I C_{1}$ and $I C_{6}$ are binding. By using 
the same procedure by ignoring other constraints to solve the program, we find that given the solutions $P C_{2}$ is not satisfied.

In this case, we guess $I C_{7}, I C_{1}, I C_{6}, P C_{2}$ and $P C_{4}$ are binding. In this case, we maximize the utility of the outsider subject to constraints $I C_{7}, I C_{1}, I C_{6}, P C_{2}$ and $P C_{4}$. The solutions are $U_{L}^{0}=\alpha_{H}^{1}\left(\theta_{H}-\theta_{L}\right)-A \sigma^{2} \alpha_{L}^{1}, U_{H}^{0}=0, U_{L}^{1}=\theta_{L}-\frac{1}{2} A \sigma^{2}+\alpha_{H}^{1}\left(\theta_{H}-\theta_{L}\right), U_{H}^{1}=\theta_{H}-\frac{1}{2} A \sigma^{2}$, $\alpha_{L}^{0}=\alpha_{H}^{1}-K \alpha_{L}^{1}, \alpha_{H}^{0}=0, \alpha_{L}^{1}=1+\frac{b_{L}^{0}}{b_{L}^{1}}$ and $\alpha_{H}^{1}=1-\frac{b_{L}^{0}+b_{L}^{1}}{b_{H}^{1}} \frac{1}{K}$. Given the solutions, ICs and PCs are satisfied if $\frac{b_{L}^{0}}{b_{L}^{1}} \leq \frac{1}{K+\frac{b_{L}^{1}}{b_{H}^{1}} \frac{1}{K}}-1$. Thus, we obtain Scenario 1 in Table 2.

Now we turn to the situation where $\frac{b_{0}^{1}}{b_{L}^{1}}>\frac{1}{K+\frac{b_{L}^{1}}{b_{H}^{1}} \frac{1}{K}}-1 . P C_{1}$ and $I C_{5}$ do not hold. Thus, we guess $I C_{7}, I C_{1}, I C_{6}, P C_{1}, P C_{2}$ and $P C_{4}$ are binding. we maximize the utility of the outsider subject to constraints $I C_{7}, I C_{1}, I C_{6}, P C_{1}, P C_{2}$ and $P C_{4}$.

The solutions are $U_{L}^{0}=U_{H}^{0}=0, U_{L}^{1}=\theta_{L}-\frac{1}{2} A \sigma^{2}+\alpha_{H}^{1}\left(\theta_{H}-\theta_{L}\right), U_{H}^{1}=\theta_{H}-\frac{1}{2} A \sigma^{2}, \alpha_{L}^{0}=$ $\alpha_{H}^{0}=0, \alpha_{L}^{1}=\frac{K}{\frac{b_{L}^{1}}{b_{H}^{1}}+K^{2}}$, and $\alpha_{H}^{1}=\frac{K^{2}}{\frac{b_{L}^{1}}{b_{H}^{1}}+K^{2}}$. In this case, all ICs and PCs are satisfied. Thus, we obtain the results as Scenario 2 in Table 2.

\section{CASE: $K \geq 1$}

In this case, $K(1-K) \leq 0$. Thus, if $0 \leq \frac{b_{L}^{1}}{b_{H}^{1}} \leq K$, we obtain that $U_{L}^{0}=U_{H}^{0}=0, U_{L}^{1}=\theta_{L}-$ $\frac{1}{2} A \sigma^{2}+\alpha_{H}^{1}\left(\theta_{H}-\theta_{L}\right), U_{H}^{1}=\theta_{H}-\frac{1}{2} A \sigma^{2}, \alpha_{L}^{0}=\alpha_{H}^{0}=0, \alpha_{L}^{1}=1$ and $\alpha_{H}^{1}=1-\frac{b_{L}^{1}}{b_{H}^{1}} \frac{1}{K}$. This represents Scenario 1 in Table 1.

However, if $\frac{b_{L}^{1}}{b_{H}^{1}}>K, I C_{2}, I C_{3}$ and $P C_{3}$ are not satisfied. By taking the same procedure as in the case where $K<1$, we obtain the results as Scenario 2 in Table 1. Q.E.D. 


\section{APPENDIX B: OUTSIDER'S EXPECTED UTILITY}

At the preopening stage, the outsider's expected utility without entry cost is as follows:

(17) $V\left(b_{L}^{0}, b_{H}^{0}, b_{L}^{1}, b_{H}^{1}\right)= \begin{cases}\frac{1}{2} A \sigma^{2} b_{L}^{1} & \frac{b_{L}^{1}}{b_{H}^{1}} \geq K \\ \frac{1}{2} A \sigma^{2} \frac{\left(b_{L}^{1}\right)^{2}+b_{L}^{1} b_{H}^{1} K(K-2)+\left(b_{H}^{1}\right)^{2} K^{2}}{b_{H}^{1} K^{2}} & \left(0 \leq \frac{b_{L}^{1}}{b_{H}^{1}}<K, K \geq 1\right) \mid \\ \frac{1}{2} A \sigma^{2} \frac{\left(b_{H}^{1}\right)^{2} K^{2}}{b_{L}^{1}+b_{H}^{1} K^{2}} & \left(K(1-K) \leq \frac{b_{L}^{1}}{b_{H}^{1}}<K, K<1\right) \\ \frac{1}{2} A \sigma^{2}\left[-b_{L}^{0} \alpha_{L}^{0}\left(\alpha_{L}^{0}+\frac{2}{K}\right)+E V^{1}\right] & 0 \leq \frac{b_{L}^{1}}{b_{H}^{1}}<K(1-K), K(1-K), \\ b_{H}^{1} & \frac{b_{L}^{0}}{b_{L}^{1}}>\frac{1}{K+\frac{b_{L}^{1}}{b_{H}^{1}} \frac{1}{K}}-1, K<1 \\ & \frac{b_{L}^{0}}{b_{L}^{1}} \leq \frac{1}{K+\frac{b_{L}^{1}}{b_{H}^{1}} \frac{1}{K}}-1, K<1,\end{cases}$

where $\alpha_{L}^{0}=1-\frac{b_{L}^{0}+b_{L}^{1}}{b_{H}^{1} K}-\frac{\left(b_{L}^{0}+b_{L}^{1}\right) K}{b_{L}^{1}}$ and $E V^{1}=b_{L}^{1}+b_{H}^{1}-\frac{\left(b_{L}^{0}\right)^{2}}{b_{L}^{1}}-\frac{2 b_{L}^{1}}{K}+\frac{\left(b_{L}^{1}\right)^{2}-\left(b_{L}^{0}\right)^{2}}{b_{L}^{1} K^{2}}$.

\section{APPENDIX C: PROOF OF PROPOSITION 1}

We first prove that strategy 1 is always an equilibrium. In strategy 1 , the insider chooses to preannounce $\left(q_{1}, l_{1}\right)$ if he observes $(\tilde{e}, \tilde{s}) \in\left\{\left(1, \theta_{H}\right),\left(1, \theta_{L}\right)\right\}$ and preannounce $\left(q_{2}, l_{2}\right)$ if he observes $(\tilde{e}, \tilde{s}) \in\left\{\left(0, \theta_{H}\right),\left(0, \theta_{L}\right)\right\}$. At the preopening stage, if the insider observes $\left(1, \theta_{H}\right)$ or $\left(1, \theta_{L}\right)$, he has no incentive to preannounce message $\left(q_{2}, l_{2}\right)$, where the outsider chooses to stay out of the market and no trading occurs. He also has no incentive to switch to other offequilibrium strategies. This is because if he switches to an off-equilibrium strategy, by plugging the prior beliefs into equation (17), the outsider's utility is

$$
V_{0}=V\left(\frac{1}{2}(1-\lambda), \frac{1}{2}(1-\lambda), \frac{1}{2} \lambda, \frac{1}{2} \lambda\right)= \begin{cases}\frac{1}{4} \lambda A \sigma^{2} & K<1 \\ \frac{1-2 K+2 K^{2}}{4 K^{2}} \lambda A \sigma^{2} & K \geq 1\end{cases}
$$


The outsider decides to enter if $c \leq V_{0}$. Given entry, the trading profiles at the trading stage will be as Scenario 1 in Table 1 or Scenario 4 in Table 2. The outsider's total expected utility given entry cost is $\max \left\{V_{0}-c, 0\right\}$.

However, if the insider uses strategy 1 , the outsider's utility without entry cost conditional on message $\left(q_{1}, l_{1}\right)$ is

$$
V_{1,1}=V\left(0,0, \frac{1}{2}, \frac{1}{2}\right)= \begin{cases}\frac{1}{4} A \sigma^{2} & K<1 \\ \frac{1-2 K+2 K^{2}}{4 K^{2}} A \sigma^{2} & K \geq 1\end{cases}
$$

The outsider's decides to enter if $c \leq V_{1,1}$. Given entry, the trading profiles at the trading stage will be the same as the outsider holding prior belief, i.e., the off-equilibrium case. The outsider's expected utility given entry cost is $\lambda \max \left\{V_{1,1}-c, 0\right\}$. We can see that i) $V_{1,1}>V_{0}$, the outsider is more likely to enter if the insider uses strategy 1 than off-equilibrium strategies. Given more entry, the insider has higher probability to obtain informational rents. Thus, the insider is better off with strategy 1 , and ii) $\lambda \max \left\{V_{1,1}-c, 0\right\}>\max \left\{V_{0}-c, 0\right\}$, the outsider is also better off with strategy 1 . Thus, the insider observing $\left(1, \theta_{H}\right)$ or $\left(1, \theta_{L}\right)$ has no incentive to preannounce $\left(q_{2}, l_{2}\right)$ or other off-equilibrium strategies.

If the insider observes $\left(0, \theta_{H}\right)$ or $\left(0, \theta_{L}\right)$, he also has no incentive to preannounce $\left(q_{1}, l_{1}\right)$ or other off-equilibrium strategies, because he always gets a payoff 0 . As a result, strategy 1 is always an equilibrium.

Similarly, we can take the same procedure to show that strategies 2, 3, 4 and 5 are always be equilibria. Q.E.D.

\section{APPENDIX D: PROOF OF PROPOSITION 2}

First, strategy 2 is the same as strategy 1 since preannouncing private signals when the liquidity shock is 0 does not add any additional value.

Second, we show that strategy 1 dominates strategy 3 . In strategy 1 , the outsider stays out of the market if the message preannounced by the insider is $\left(q_{2}, l_{2}\right)$ at the preopening stage since there is no liquidity need. The outsider enters into the market given message $\left(q_{1}, l_{1}\right)$ at the 
preopening stage if $c \leq V_{1,1}$, where the value $V_{1,1}$ is as equation (19). Given entry, the trading profiles are as Scenario 1 in Table 1 if $K \geq 1$ or as Scenario 4 in Table 2 if $K<1$.

In strategy 3 , the outsider stays out of the market given message $\left(q_{2}, l_{2}\right)$ since there is no liquidity need. The outsider enters into the market given that message is $\left(q_{1}, l_{1}\right)$ if $c \leq V_{1,3}$, where

(20) $V_{1,3}=V\left(\frac{1-\lambda}{1+\lambda}(1-p), \frac{1-\lambda}{1+\lambda} p, \frac{\lambda}{1+\lambda}, \frac{\lambda}{1+\lambda}\right)= \begin{cases}\frac{1}{2} \frac{\lambda}{1+\lambda} A \sigma^{2} & K<1 \\ \frac{\left(1-2 K+2 K^{2}\right) \lambda}{2 K^{2}(1+\lambda)} A \sigma^{2} & K \geq 1 .\end{cases}$

Given entry, the trading profiles are also as Scenario 1 in Table 1 if $K \geq 1$ or as Scenario 4 in Table 2 if $K<1$.

By comparing the two strategies, we can see that given entry, the insider gets exactly the same payoff. The only difference for the two strategies lies in the entry decision of the outsider given different messages. It is easy to see that $V_{1,3}<V_{1,1}$. Thus, with strategy 1 , the outsider is more likely to enter, which benefits the insider to be more likely to obtain the informational rent. In addition, we compare the expected utility of the outsider for two strategies. In case of strategy 1 , the outsider's total expected utility is $\lambda \max \left\{V_{1,1}-c, 0\right\}$. In case of strategy 3 , the outsider's total expected utility is $\frac{1}{2}(1+\lambda) \max \left\{V_{1,3}-c, 0\right\}$. We can see the former utility is greater than the latter utility. Therefore, compared with strategy 3 , both the insider and the outsider will be better off in strategy 1.

Similarly, we take the same approach to show that strategy 1 also dominates strategies 4 and 5. Q.E.D.

\section{APPENDIX E: PROOF OF PROPOSITION 3}

We prove that strategy $\mathrm{j}$, where $j=6, \ldots, 15$, is an equilibrium under the four scenarios in Proposition 3.

If the outsider receives message $\left(q_{3}, l_{3}\right)$ or $\left(q_{4}, l_{4}\right)$, she will choose to stay out of the market since there is no liquidity need. The outsider's belief $\frac{b_{L}^{1}}{b_{H}^{1}}$ at the trading stage is $\frac{1-p}{p}$ for message $\left(q_{1}, l_{1}\right), \frac{p}{1-p}$ for message $\left(q_{2}, l_{2}\right)$, and 1 for off-equilibrium strategies. 
First, we consider the case where $K \leq \frac{1-p}{p}$. Since $\frac{p}{1-p}>1>\frac{1-p}{p} \geq K$, we obtain that the outsider's belief $\frac{b_{L}^{1}}{b_{H}^{1}}$ is no less than $K$ regardless of the message she receives at the preopening stage. In this case, given that the outsider enters, the trading profiles is always as Scenario 4 in Table 2. That is, the insider always obtains his outside option value regardless of his message at the preopening stage. In this case, the insider has no incentive to deviate from strategy $\mathrm{j}$.

Second, we consider the case where $\frac{1-p}{p}<K \leq 1$ and $c>V_{1, j}$. Since $\frac{p}{1-p}>1 \geq K>\frac{1-p}{p}$, we have: If the outsider receives the message $\left(q_{1}, l_{1}\right)$, the outsider's belief $\frac{b_{L}^{1}}{b_{H}^{1}}$ is less than $K$. In this case, given entry, the insider can obtain some positive informational rent in the trading stage. If the outsider receives $\left(q_{2}, l_{2}\right)$ or other off-equilibrium messages, the outsider's belief $\frac{b_{L}^{1}}{b_{H}^{1}}$ is no less than $K$ and the trading profiles would be always as Scenario 4 in Table 2. In this case, given entry of the outsider, the insider always obtains outside option value. $c>V_{1, j}$ ensures the outsider will choose to stay out of the market if the insider takes strategy $\mathrm{j}$ and send message $\left(q_{1}, l_{1}\right)$, in which case the insider cannot obtain the informational rent at the trading stage and precludes the possibility of the insider with the asset to mimic the high quality signal. Therefore, the insider has no incentive to deviate from strategy $\mathrm{j}$.

Third, we consider the case where if $1<K \leq \frac{p}{1-p}$ and $c>\max \left\{V_{1, j}, V_{0}\right\}$. Since $\frac{p}{1-p} \geq K>$ $1>\frac{1-p}{p}$, we have: If the outsider receives message $\left(q_{1}, l_{1}\right)$ or other off-equilibrium messages, the outsider's belief $\frac{b_{L}^{1}}{b_{H}^{1}}$ is less than $K$. In this case, given entry of the outsider, the insider can obtain some positive informational rent in the trading stage. If the outsider receives message $\left(q_{2}, l_{2}\right)$, the outsider's belief $\frac{b_{L}^{1}}{b_{H}^{1}}$ is no less than $K$, and the trading profiles would be always as Scenario 2 in Table 1. In this case, given entry of the outsider, the insider always obtains outside option value. $c>\max \left\{V_{1, j}, V_{0}\right\}$ ensures that the outsider will choose to stay out of the market if the insider takes strategy $\mathrm{j}$ and send message $\left(q_{1}, l_{1}\right)$ or takes other off-equilibrium messages at the preopening stage. This precludes the possibility of the insider with the asset to mimic a high quality signal or switch to an off-equilibrium strategies. Therefore, the insider has no incentive to deviate from strategy $\mathrm{j}$.

Fourth, we consider the case where $K>\frac{p}{1-p}$ and $c>\max \left\{V_{1, j}, V_{2, j}, V_{0}\right\}$. Since $K>\frac{p}{1-p}>$ $1>\frac{1-p}{p}$, we obtain that the outsider's $\frac{b_{L}^{1}}{b_{H}^{1}}$ is less than $K$ if she receives $\left(q_{1}, l_{1}\right),\left(q_{2}, l_{2}\right)$ or other off-equilibrium messages at the preopening stage. In this case, given entry, the insider can ob- 
tain some positive informational rent in the trading stage, which decreases with $\frac{b_{L}^{1}}{b_{H}^{1}}$. Therefore, the insider has an incentive to report $\left(q_{1}, l_{1}\right)$ to pretend to observe high quality signal. The condition $c>\max \left\{V_{1, j}, V_{2, j}, V_{0}\right\}$ ensures that the outsider always stays out of the market and the insider can only obtain outside option value. In this case, there is no trading. Thus, the insider also has no incentive to deviate from strategy j. Q.E.D.

\section{APPENDIX F: PROOF OF PROPOSITION 4}

Case 1: $K \leq \frac{1-p}{p}$

In this case, any category II strategy is an equilibrium. In the following, we show that strategy 6 dominates all other category II strategies. Since the insider always obtains the outside option value, we show that strategy 6 generates the maximum payoff for the outsider.

By summarizing from category II strategies, we can see that the insider chooses to preannounce $\left(q_{1}, l_{1}\right)$ only if he observes private information: i) $\left(1, \theta_{H}\right)$, ii) $\left\{\left(1, \theta_{H}\right),\left(0, \theta_{H}\right)\right\}$, iii) $\left\{\left(1, \theta_{H}\right),\left(0, \theta_{L}\right)\right\}$ or iv) $\left\{\left(1, \theta_{H}\right),\left(0, \theta_{H}\right),\left(0, \theta_{L}\right)\right\}$. We calculate and compare the expected utilities of the outsider at the preopening stage for these four situations.

In situation $i)$, the expected utility of the outsider is $\frac{1}{2} \lambda \max \left\{\frac{1}{2}(1-p) A \sigma^{2}-c, 0\right\}$, where $\frac{1}{2} \lambda$ is the probability of the insider to observe $\left(1, \theta_{H}\right)$ and $\frac{1}{2}(1-p) A \sigma^{2}$ is the expected utility of the outsider without entry cost conditional on $\left(q_{1}, l_{1}\right)$ (we can obtain it from equation (17)). Similarly, in situation ii), the expected utility of the outsider is $\frac{1}{2} \max \left\{\frac{1}{2} \lambda(1-p) A \sigma^{2}-c, 0\right\}$. In situation iii), the expected utility of the outsider is $\frac{1}{2} \max \left\{\frac{1}{2} \lambda(1-p) A \sigma^{2}-c, 0\right\}$. In situation iv), the expected utility of the outsider is $\frac{1}{2}(2-\lambda) \max \left\{\frac{1}{2} \frac{\lambda}{2-\lambda}(1-p) A \sigma^{2}-c, 0\right\}$. Because $1>\lambda>\frac{\lambda}{2-\lambda}$, we obtain that the outsider get the maximum payoff in situation $\mathrm{i}$ ).

Similarly, we can also see that the insider chooses to preannounce $\left(q_{2}, l_{2}\right)$ in category II strategies only if he observes private information: i) $\left(1, \theta_{L}\right)$, ii) $\left\{\left(1, \theta_{L}\right),\left(0, \theta_{H}\right)\right\}$, iii) $\left\{\left(1, \theta_{L}\right),\left(0, \theta_{L}\right)\right\}$ or iv) $\left\{\left(1, \theta_{L}\right),\left(0, \theta_{H}\right),\left(0, \theta_{L}\right)\right\}$. In situation i), the expected utility of the outsider is $\frac{1}{2} \lambda \max \left\{\frac{1}{2} p A \sigma^{2}-c, 0\right\}$. In situation ii), the expected utility of the outsider is $\frac{1}{2} \max \left\{\frac{1}{2} \lambda p A \sigma^{2}-c, 0\right\}$. In situation iii), the expected utility of the outsider is $\frac{1}{2} \max \left\{\frac{1}{2} \lambda p A \sigma^{2}-c, 0\right\}$. In situation iv), the expected utility of the outsider is 
$\frac{1}{2}(2-\lambda) \max \left\{\frac{1}{2} \frac{\lambda}{2-\lambda} p A \sigma^{2}-c, 0\right\}$. Because $1>\lambda>\frac{\lambda}{2-\lambda}$, we also obtain that the outsider get the maximum payoff in situation i).

Regarding message $\left(q_{3}, l_{3}\right)$ or $\left(q_{4}, l_{4}\right)$, the outsider always chooses to stay out of the market since there is no liquidity need.

Therefore, in the case where $K \leq \frac{1-p}{p}$, the strategy that generates the maximum payoff for the outsider, i.e., dominates other category II strategies, is strategy 6, i.e., the insider preannounces $\left(q_{1}, l_{1}\right)$ if he observes $\left(1, \theta_{H}\right),\left(q_{2}, l_{2}\right)$ if he observes $\left(1, \theta_{L}\right),\left(q_{3}, l_{3}\right)$ otherwise (Strategy 7 is equivalent to strategy 6 since preannouncing private signals adds no value when there is no liquidity shock).

Case 2: $\frac{1-p}{p}<K \leq \frac{p}{1-p}$

In this case, since the insider always obtains the outside option value, we show that strategy 14 generates the maximum payoff for the outsider. In equilibrium, the outsider always chooses to stay out of the market if the insider preannounces $\left(q_{1}, l_{1}\right),\left(q_{3}, l_{3}\right)$ or $\left(q_{4}, l_{4}\right)$. The only situation that the outsider can obtain a positive payoff is that the insider preannounces $\left(q_{2}, l_{2}\right)$.

From the analysis in Case 1, we know that the outsider gets the maximimum payoff for the message $\left(q_{2}, l_{2}\right)$ in the case where the insider preannounces this message only if he observes private information $\left(1, \theta_{L}\right)$. In addition, the condition to ensure that the outsider can credibly punish the insider by staying out of the market if she receives the message $\left(q_{1}, l_{1}\right)$ is $c>V_{1, j}$, where $j=6, \ldots, 15$. The insider chooses to preannounce $\left(q_{1}, l_{1}\right)$ only if he observes private information: i) $\left(1, \theta_{H}\right)$, ii) $\left\{\left(1, \theta_{H}\right),\left(0, \theta_{H}\right)\right\}$, iii) $\left\{\left(1, \theta_{H}\right),\left(0, \theta_{L}\right)\right\}$ or iv) $\left\{\left(1, \theta_{H}\right),\left(0, \theta_{H}\right),\left(0, \theta_{L}\right)\right\}$. In the following, we show that the value of $V_{1, j}$ is the smallest in situation iv). If the insider preannounces $\left(q_{1}, l_{1}\right)$, the outsider's belief $\frac{b_{L}^{1}}{b_{H}^{1}}=\frac{1-p}{p}$ for all the category II strategies.

If $K \geq 1$, or $K<1$ and $\frac{1-p}{p} \geq K(1-K)$, the trading profiles are as Scenario 1 in Table 1 or Scenario 3 in Table 2 . In this case, in situation i), $V_{1, j}=\frac{1+\left(-2-2 K+K^{2}\right) p+(1+2 K) p^{2}}{2 K^{2} p} A \sigma^{2}$. In situation ii), $V_{1, j}=\frac{1+\left(-2-2 K+K^{2}\right) p+(1+2 K) p^{2}}{2 K^{2} p} \lambda A \sigma^{2}$. In situation iii), $V_{1, j}=\frac{1+\left(-2-2 K+K^{2}\right) p+(1+2 K) p^{2}}{2 K^{2} p} \lambda A \sigma^{2}$. In situation iv), $V_{1, j}=\frac{1+\left(-2-2 K+K^{2}\right) p+(1+2 K) p^{2}}{2 K^{2} p} \frac{\lambda}{2-\lambda} A \sigma^{2}$. It is easy to see that $V_{1, j}$ is the smallest in situation iv).

Similarly, we can take the same approach to show $V_{1, j}$ is also the smallest in situation iv) when $K<1$ and $\frac{1-p}{p}<K(1-K)$. Therefore, strategy 14 , i.e., the insider preannounces $\left(q_{1}, l_{1}\right)$ 
if he observes $(\tilde{e}, \tilde{s}) \in\left\{\left(1, \theta_{H}\right),\left(0, \theta_{H}\right),\left(0, \theta_{L}\right)\right\}$, and $\left(q_{2}, l_{2}\right)$ if he observes $\left(1, \theta_{L}\right)$, generates the maximum payoff for the outsider and the condition under which that equilibrium exists is the easiest to be satisfied.

Case 2: $K>\frac{p}{1-p}$

In this case, a category II strategy can be equilibrium only if $c>\max \left\{V_{0}, V_{1, j}, V_{2, j}\right\}$. That is, no trading occurs in any of the category II strategies. Q.E.D.

\section{APPENDIX G: PROOF OF PROPOSITION 5}

Case 1: $K \leq \frac{1-p}{p}$ :

In this case, $K \leq \frac{1-p}{p}<1<\frac{p}{1-p}$. The insider obtains outside option value in both equilibria of strategy 1 and strategy 6 . In the following, we compare the total expected payoff of the outsider in strategy 1 and strategy 6.

From equation (19), we can see that the total expected utility of the outsider in strategy 1 in this parameter range is

(21) $\lambda \max \left\{\frac{1}{4} A \sigma^{2}-c, 0\right\}$.

The total expected utility of the outsider in strategy 6 is

(22) $\frac{1}{2} \lambda \max \left\{\frac{1}{2}(1-p) A \sigma^{2}-c, 0\right\}+\frac{1}{2} \lambda \max \left\{\frac{1}{2} p A \sigma^{2}-c, 0\right\}$.

We can see that $\frac{1}{2} \lambda \max \left\{\frac{1}{2}(1-p) A \sigma^{2}-c, 0\right\}+\frac{1}{2} \lambda \max \left\{\frac{1}{2} p A \sigma^{2}-c, 0\right\} \geq \lambda \max \left\{\frac{1}{4} A \sigma^{2}-c, 0\right\}$. That is the outsider gets higher expected utility in strategy 6 than strategy 1 . Therefore, in this case, the insider chooses strategy 6 at the preopening stage.

Case 2: $\frac{1-p}{p}<K \leq \frac{p}{1-p}$ :

In the case where $\frac{1-p}{p}<K \leq 1$, the insider obtains the outside option value in both strategy 1 and strategy 14. Thus, the optimal equilibrium should be the one which generates a larger total expected utility for the outsider. The total expected utility of the outsider in strategy 1 is as equation (21). The total expected utility of the outsider in strategy 14 is $\frac{1}{2} \lambda\left\{\frac{1}{2} p A \sigma^{2}-c, 0\right\}$. 
After a comparison, we can obtain that the outsider gets a higher utility from strategy 1 if $c \leq \frac{1}{2}(1-p) A \sigma^{2}$, and otherwise gets a higher utility from strategy 14 .

In addition, we know that strategy 1 is always an equilibrium while strategy 14 is an equilibrium only if $c>V_{1,14}$, where $V_{1,14}=V\left(\frac{1-\lambda}{2-\lambda}, \frac{1-\lambda}{2-\lambda}, \frac{\lambda}{2-\lambda}(1-p), \frac{\lambda}{2-\lambda} p\right)$. Therefore, the outsider chooses strategy 1 if $c \leq \max \left\{\frac{1}{2}(1-p) A \sigma^{2}, V_{1,14}\right\}$, and strategy 14 if $c>\max \left\{\frac{1}{2}(1-\right.$ p) $\left.A \sigma^{2}, V_{1,14}\right\}$. That is $c^{\prime}=\max \left\{\frac{1}{2}(1-p) A \sigma^{2}, V_{1,14}\right\}$.

In the case where $1<K \leq \frac{p}{1-p}$, if $c \leq \frac{1}{4} A \sigma^{2}$, the insider obtains positive informational rent from strategy 1 while outside option value from strategy 14 . Thus, the insider always chooses strategy 1. If $c>\frac{1}{4} A \sigma^{2}$, the insider always obtains outside option value from both strategies. Strategy 14 is an equilibrium only if $c>V_{1,14}$. Therefore, the outsider chooses strategy 1 if $c \leq \max \left\{\frac{1}{4} A \sigma^{2}, V_{1,14}\right\}$ and strategy 14 if $c>\max \left\{\frac{1}{4} A \sigma^{2}, V_{1,14}\right\}$. That is, $c^{\prime}=\max \left\{\frac{1}{4} A \sigma^{2}, V_{1,14}\right\}$.

By summarizing, the value of $c^{\prime}$ is as follows

$$
c^{\prime}= \begin{cases}\max \left\{\frac{1}{2}(1-p) A \sigma^{2}, V_{1,14}\right\} & \frac{1-p}{p}<K \leq 1 \\ \max \left\{\frac{1}{4} A \sigma^{2}, V_{1,14}\right\} & 1<K \leq \frac{p}{1-p}\end{cases}
$$

where $V_{1,14}=V\left(\frac{1-\lambda}{2-\lambda}, \frac{1-\lambda}{2-\lambda}, \frac{\lambda}{2-\lambda}(1-p), \frac{\lambda}{2-\lambda} p\right)$.

Case 3: $K>\frac{p}{1-p}$

In this case, there is no trading for any category II strategies, including strategy 14 . Therefore, the insider will choose to use strategy 1 at the preopening stage. Q.E.D.

\section{APPENDIX H: PROOF OF PROPOSITION 6}

Without a preopening stage, the outsider decides to enter if $c \leq V_{0}$, where $V_{0}=V\left(\frac{1}{2}(1-\right.$ $\left.\lambda), \frac{1}{2}(1-\lambda), \frac{1}{2} \lambda, \frac{1}{2} \lambda\right)$ as equation (18). In equilibrium of strategy 1 , the outsider enters given the liquidity need is preannnounced if $c \leq V_{1,1}$, where $V_{1,1}=V\left(0,0, \frac{1}{2}, \frac{1}{2}\right)$ as equation (19). It is easier to see that $V_{0}=\lambda V_{1,1}<V_{1,1}$. Thus, when $c \leq V_{0}$, the outsider always enters into the trading stage without preopening stage while she can enter more efficiently only if the liquidity need is preannounced in strategy 1 . When $V_{0}<c \leq V_{1,1}$, there is no trading without preopening 
stage but trading exists if the liquidity need is preannounced at the preopening stage in strategy 1. Q.E.D.

\section{APPENDIX I: PROOF OF PROPOSITION 7}

\section{Case I: Strategy 14}

We focus on the case where $\frac{1-p}{p}<K \leq \frac{p}{1-p}$ and $c \in\left(V_{1,14}, V_{2,14}\right]$, where $V_{1,14}=$ $V\left(\frac{1-\lambda}{2-\lambda}, \frac{1-\lambda}{2-\lambda}, \frac{\lambda}{2-\lambda}(1-p), \frac{\lambda}{2-\lambda} p\right), V_{2,14}=V(0,0, p, 1-p)$ and $V_{1,14}<V_{2,14}$. In this case, the equilibrium of strategy 14 involves trading if the insider preannounces $\left(q_{2}, l_{2}\right)$. The main objective is to check whether strategy 14 at the preopening stage can improve liquidity provision compared with the case without preopening stage.

Without a preopening stage, the outsider decides to enter if $c \leq V_{0}$, where $V_{0}=V\left(\frac{1}{2}(1-\right.$ $\left.\lambda), \frac{1}{2}(1-\lambda), \frac{1}{2} \lambda, \frac{1}{2} \lambda\right)$ as equation (18). With strategy 14 , the outsider enters if $c \in\left(V_{1,14}, V_{2,14}\right]$. $V_{2,14}=\frac{1}{2} p A \sigma^{2}$, which is always greater than $V_{0}$.

If $V_{1,14} \geq V_{0}$, the adoption of strategy 14 always helps increase liquidity provision when $c \in\left(V_{1,14}, V_{2,14}\right]$. Because in this range, there is no trading without preopening stage.

If $V_{1,14}<V_{0}$, when $c \in\left(V_{1,14}, V_{0}\right]$, the outsider always enters into the trading stage without the preopening stage. However, the outsider only enters if the insider owns the asset and observes a low quality signal in strategy 14 . In this case, liquidity is less provided in the equilibrium of strategy 14. When $c \in\left(V_{0}, V_{2,14}\right]$, there is no trading without the preopening stage while there exists trading in the equilibrium of strategy 14 . Therefore, strategy 14 improves liquidity provision except when $V_{1,14}<V_{0}$ and $c \in\left(V_{1,14}, V_{0}\right]$.

\section{Case II: Strategy 6}

In the case where $K \leq \frac{1-p}{p}$, for strategy 6 , the outsider always enters into the trading stage when there is liquidity need if $c \leq V_{1,6}$, where $V_{1,6}=\frac{1}{2}(1-p) A \sigma^{2}$, enters only if the insider preannounces $\left(q_{2}, l_{2}\right)$ if $V_{1,6}<c \leq V_{2,6}$, where $V_{2,6}=\frac{1}{2} p A \sigma^{2}$, and stays out of the market if $c>V_{2,6}$. Without a preopening stage, the outsider always enters into the trading stage if $c \leq V_{0}$, where $V_{0}=\frac{1}{4} \lambda A \sigma^{2}$.

Thus, after a comparison, we can see that if $V_{0} \leq V_{1,6}$, the adoption of strategy 6 always improves liquidity provision. If $V_{0}>V_{1,6}$, when $c \in\left[0, V_{1,6}\right]$, the outsider always enters into the 
trading stage in the market without preopening stage while chooses to enter with strategy 6 more efficiently only if the liquidity needs is preannounced. When $c \in\left(V_{1,6}, V_{0}\right]$, the outsider always enters into the trading stage in the market without preopening stage while chooses to enter only if the insider owns the asset and observes a low quality signal. In this case, the liquidity is less provided in the equilibrium of strategy 6 since there is no liquidity provision when the insider owns the asset and observes a high quality signal in strategy 6 . When $c \in\left(V_{0}, V_{2,6}\right]$, there is no trading in the market without preopening stage but trading exists if the insider owns the asset and observes a low quality signal in strategy 6 . Therefore, strategy 6 improves liquidity provision except when $V_{1,6}<V_{0}$ and $c \in\left(V_{1,6}, V_{0}\right]$. Q.E.D.

\section{REFERENCES}

Admati, A. R. and Pfleiderer, P. (1991). Sunshine trading and financial market equilibrium. Review of Financial Studies, 4 (3), 443-481.

Barclay, M. J. and Hendershott, T. (2003). Price discovery and trading after hours. Review of Financial Studies, 16 (4), 1041-1073.

- and - (2008). A comparison of trading and non-trading mechanisms for price discovery. Journal of Empirical Finance, 15 (5), 839-849.

BARUCH, S. (2005). Who benefits from an open limit-order book? Journal of Business, 78 (4).

Bhattacharya, U. and SPIEgEL, M. (1991). Insiders, outsiders, and market breakdowns. Review of Financial Studies, 4 (2), 255-282.

Biais, B., Hillion, P. and SpatT, C. (1999). Price discovery and learning during the preopening period in the paris bourse. Journal of Political Economy, 107 (6), 1218-1248.

—, Martimort, D. and Rochet, J.-C. (2000). Competing mechanisms in a common value environment. Econometrica, 68 (4), 799-837.

Cao, C., Ghysels, E. and Hatheway, F. (2000). Price discovery without trading: Evidence from the nasdaq preopening. Journal of Finance, 55 (3).

DiA, M. and Pouget, S. (2011). Sunshine trading in an african stock market. Managerial Finance, 37 (3), 257-274. 
Grossman, S. J. and Miller, M. H. (1988). Liquidity and market structure. Journal of Finance, 43 (3).

JiAnG, C. X., LikitAPIWAT, T. and MCINISH, T. H. (2012). Information content of earnings announcements: Evidence from after-hours trading. Journal of Financial and Quantitative Analysis, 47 (6), 1303-1330.

LAFFONT, J.-J. and MASKIN, E. S. (1990). The efficient market hypothesis and insider trading on the stock market. Journal of Political Economy, 98 (1), 70-93.

Medrano, L. A. and Vives, X. (2001). Strategic behavior and price discovery. Rand Journal of Economics, 32 (2), 221-248.

Pagano, M. S., Peng, L. and Schwartz, R. A. (2013). A call auction's impact on price formation and order routing: Evidence from the nasdaq stock market. Journal of Financial Markets, 16 (2), 331-361.

Spatt, C. and SRIVASTAVA, S. (1991). Preplay communication, participation restrictions, and efficiency in initial public offerings. Review of Financial Studies, 4 (4), 709-726.

VIVES, X. (1995). The speed of information revelation in a financial market mechanism. Journal of Economic Theory, 67 (1), 178-204. 
TABLES

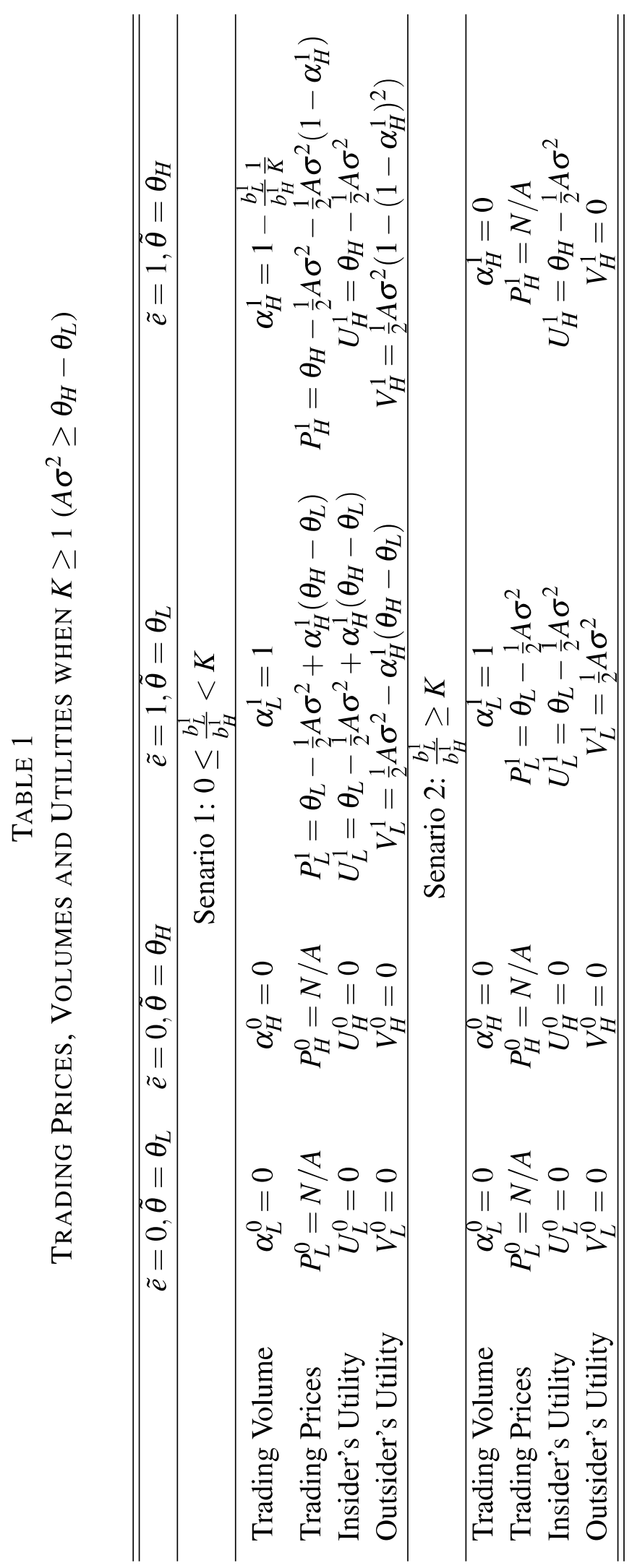




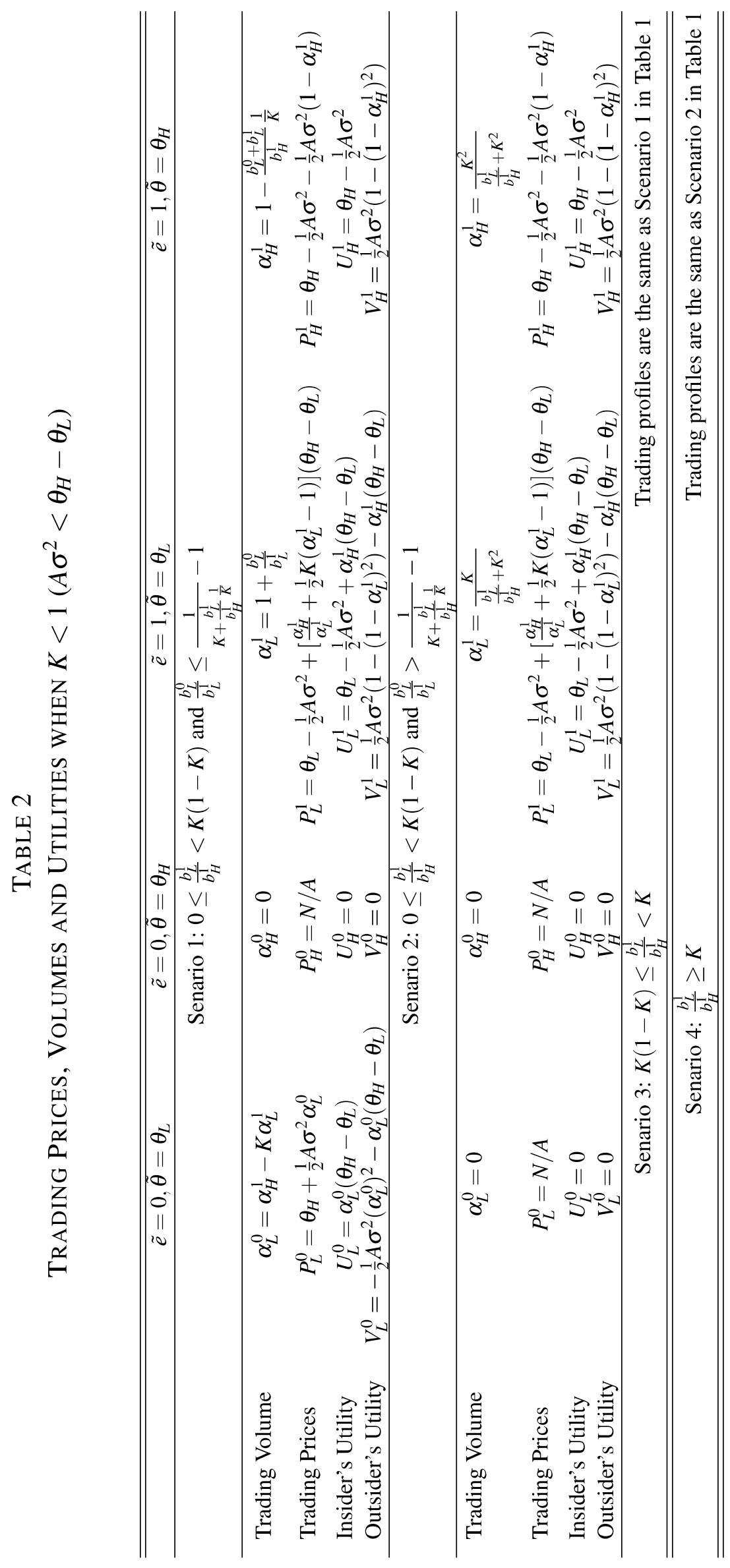


TABLE 3

CATEGORY I PURE STRATEGIES FOR THE INSIDER AT THE PREOPENING STAGE

\begin{tabular}{|c|c|c|c|}
\hline & Insider information $(\tilde{e}, \tilde{s})$ & Non-binding limit offer & Outsider's belief $\left(b_{L}^{0}, b_{H}^{0}, b_{L}^{1}, b_{H}^{1}\right)$ \\
\hline \multirow{2}{*}{ Strategy 1} & $\left.\begin{array}{ll}(1, & \left.\theta_{H}\right) \\
(1, & \theta_{L}\end{array}\right)$ & $\left(q_{1}, l_{1}\right)$ & $\left(0,0, \frac{1}{2}, \frac{1}{2}\right)$ \\
\hline & 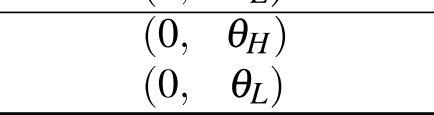 & $\left(q_{2}, l_{2}\right)$ & $\left(\frac{1}{2}, \frac{1}{2}, 0,0\right)$ \\
\hline \multirow{3}{*}{ Strategy 2} & $\begin{array}{ll}(1, & \left.\theta_{H}\right) \\
(1, & \left.\theta_{L}\right)\end{array}$ & $\left(q_{1}, l_{1}\right)$ & $\left(0,0, \frac{1}{2}, \frac{1}{2}\right)$ \\
\hline & $\left(0, \theta_{H}\right)$ & $\left(q_{2}, l_{2}\right)$ & $(1-p, p, 0,0)$ \\
\hline & $\left(0, \theta_{L}\right)$ & $\left(q_{3}, l_{3}\right)$ & $(\mathrm{p}, 1-\mathrm{p}, 0,0)$ \\
\hline \multirow[t]{2}{*}{ Strategy 3} & 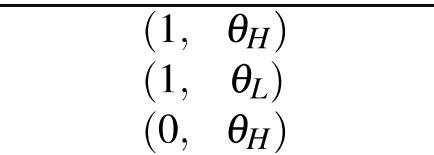 & $\left(q_{1}, l_{1}\right)$ & $\left(\frac{1-\lambda}{1+\lambda}(1-p), \frac{1-\lambda}{1+\lambda} p, \frac{\lambda}{1+\lambda}, \frac{\lambda}{1+\lambda}\right)$ \\
\hline & $\left(0, \theta_{L}\right)$ & $\left(q_{2}, l_{2}\right)$ & $(p, 1-p, 0,0)$ \\
\hline \multirow[t]{2}{*}{ Strategy 4} & 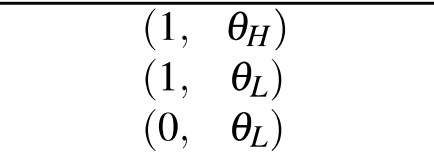 & $\left(q_{1}, l_{1}\right)$ & $\left(\frac{1-\lambda}{1+\lambda} p, \frac{1-\lambda}{1+\lambda}(1-p), \frac{\lambda}{1+\lambda}, \frac{\lambda}{1+\lambda}\right)$ \\
\hline & $\left(0, \theta_{H}\right)$ & $\left(q_{2}, l_{2}\right)$ & $(1-p, p, 0,0)$ \\
\hline Strategy 5 & 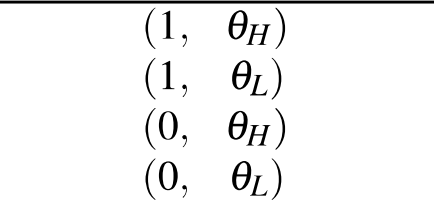 & $\left(q_{1}, l_{1}\right)$ & $\left(\frac{1}{2}(1-\lambda), \frac{1}{2}(1-\lambda), \frac{1}{2} \lambda, \frac{1}{2} \lambda\right)$ \\
\hline
\end{tabular}


TABLE 4

CATEGORY II PURE STRATEGIES FOR THE INSIDER AT THE PREOPENING STAGE

\begin{tabular}{|c|c|c|c|}
\hline & Insider information $(\tilde{e}, \tilde{s})$ & Non-binding limit offer & Outsider's belief $\left(b_{L}^{0}, b_{H}^{0}, b_{L}^{1}, b_{H}^{1}\right)$ \\
\hline \multirow{3}{*}{ Strategy 6} & $\left(1, \theta_{H}\right)$ & $\left(q_{1}, l_{1}\right)$ & $(0,0,1-p, p)$ \\
\hline & $\left(1, \theta_{L}\right)$ & $\left(q_{2}, l_{2}\right)$ & $(0,0, p, 1-p)$ \\
\hline & $\begin{array}{ll}(0, & \left.\theta_{H}\right) \\
(0, & \left.\theta_{L}\right)\end{array}$ & $\left(q_{3}, l_{3}\right)$ & $\left(\frac{1}{2}, \frac{1}{2}, 0,0\right)$ \\
\hline \multirow{4}{*}{ Strategy 7} & $\left(1, \theta_{H}\right)$ & $\left(q_{1}, l_{1}\right)$ & $(0,0,1-p, p)$ \\
\hline & $\left(1, \theta_{L}\right)$ & $\left(q_{2}, l_{2}\right)$ & $(0,0, p, 1-p)$ \\
\hline & $\left(0, \theta_{H}\right)$ & $\left(q_{3}, l_{3}\right)$ & $(1-p, p, 0,0)$ \\
\hline & $\left(0, \theta_{L}\right)$ & $\left(q_{4}, l_{4}\right)$ & $(p, 1-p, 0,0)$ \\
\hline \multirow{2}{*}{ Strategy 8} & 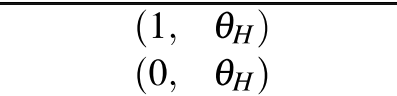 & $\left(q_{1}, l_{1}\right)$ & $((1-\lambda)(1-p),(1-\lambda) p, \lambda(1-p), \lambda p)$ \\
\hline & $\left.\begin{array}{ll}(1, & \left.\theta_{L}\right) \\
(0, & \theta_{L}\end{array}\right)$ & $\left(q_{2}, l_{2}\right)$ & $((1-\lambda) p,(1-\lambda)(1-p), \lambda p, \lambda(1-p))$ \\
\hline \multirow{2}{*}{ Strategy 9} & $\begin{array}{ll}(1, & \left.\theta_{H}\right) \\
(0, & \left.\theta_{L}\right)\end{array}$ & $\left(q_{1}, l_{1}\right)$ & $((1-\lambda) p,(1-\lambda)(1-p), \lambda(1-p), \lambda p)$ \\
\hline & 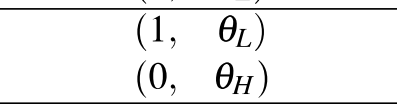 & $\left(q_{2}, l_{2}\right)$ & $((1-\lambda)(1-p),(1-\lambda) p, \lambda p, \lambda(1-p))$ \\
\hline \multirow{3}{*}{ Strategy 10} & $\left.\begin{array}{ll}(1, & \left.\theta_{H}\right) \\
(0, & \theta_{H}\end{array}\right)$ & $\left(q_{1}, l_{1}\right)$ & $((1-\lambda)(1-p),(1-\lambda) p, \lambda(1-p), \lambda p)$ \\
\hline & $\left(1, \theta_{L}\right)$ & $\left(q_{2}, l_{2}\right)$ & $(0,0, p, 1-p)$ \\
\hline & $\left(0, \theta_{L}\right)$ & $\left(q_{3}, l_{3}\right)$ & $(p, 1-p, 0,0)$ \\
\hline \multirow{3}{*}{ Strategy 11} & 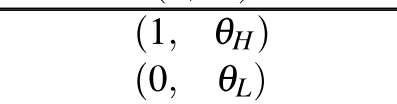 & $\left(q_{1}, l_{1}\right)$ & $((1-\lambda) p,(1-\lambda)(1-p), \lambda(1-p), \lambda p)$ \\
\hline & $\left(1, \theta_{L}\right)$ & $\left(q_{2}, l_{2}\right)$ & $(0,0, p, 1-p)$ \\
\hline & $\left(0, \theta_{H}\right)$ & $\left(q_{3}, l_{3}\right)$ & $(1-p, p, 0,0)$ \\
\hline \multirow{3}{*}{ Strategy 12} & $\left(1, \theta_{H}\right)$ & $\left(q_{1}, l_{1}\right)$ & $(0,0,1-p, p)$ \\
\hline & $\left.\begin{array}{ll}(1, & \left.\theta_{L}\right) \\
(0, & \theta_{L}\end{array}\right)$ & $\left(q_{2}, l_{2}\right)$ & $((1-\lambda) p,(1-\lambda)(1-p), \lambda p, \lambda(1-p))$ \\
\hline & $\left(0, \theta_{H}\right)$ & $\left(q_{3}, l_{3}\right)$ & $(1-p, p, 0,0)$ \\
\hline \multirow{3}{*}{ Strategy 13} & $\left(1, \theta_{H}\right)$ & $\left(q_{1}, l_{1}\right)$ & $(0,0,1-p, p)$ \\
\hline & 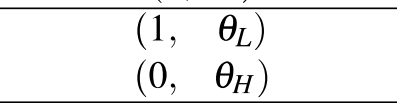 & $\left(q_{2}, l_{2}\right)$ & $((1-\lambda)(1-p),(1-\lambda) p, \lambda p, \lambda(1-p))$ \\
\hline & $\left(0, \theta_{L}\right)$ & $\left(q_{3}, l_{3}\right)$ & $(p, 1-p, 0,0)$ \\
\hline \multirow[t]{2}{*}{ Strategy 14} & $\left.\begin{array}{ll}(1, & \left.\theta_{H}\right) \\
(0, & \left.\theta_{H}\right) \\
(0, & \theta_{L}\end{array}\right)$ & $\left(q_{1}, l_{1}\right)$ & $\left(\frac{1-\lambda}{2-\lambda}, \frac{1-\lambda}{2-\lambda}, \frac{\lambda}{2-\lambda}(1-p), \frac{\lambda}{2-\lambda} p\right)$ \\
\hline & $\left(1, \theta_{L}\right)$ & $\left(q_{2}, l_{2}\right)$ & $(0,0, p, 1-p)$ \\
\hline \multirow[b]{2}{*}{ Strategy 15} & $\left(1, \theta_{H}\right)$ & $\left(q_{1}, l_{1}\right)$ & $(0,0,1-p, p)$ \\
\hline & $\begin{array}{cc}(1, & \left.\theta_{L}\right) \\
(0, & \left.\theta_{H}\right) \\
(0, & \left.\theta_{L}\right)\end{array}$ & $\left(q_{2}, l_{2}\right)$ & $\left(\frac{1-\lambda}{2-\lambda}, \frac{1-\lambda}{2-\lambda}, \frac{\lambda}{2-\lambda} p, \frac{\lambda}{2-\lambda}(1-p)\right)$ \\
\hline
\end{tabular}




\section{FIGURES}

\section{FIGURE 1}

THE TIMELINE OF THE TRADING IN THE FINANCIAL MARKET

\begin{tabular}{|c|c|c|c|c|}
\hline 'ו & & & & \\
\hline $\begin{array}{l}\text { Insider receives } \\
\text { endowment e and } \\
\text { observes signal s }\end{array}$ & $\begin{array}{l}\text { Preopening Period: } \\
\text { Insider submits } \\
\text { non-binding limit } \\
\text { order }(\mathrm{q}, 1)\end{array}$ & $\begin{array}{l}\text {-Outsider decides } \\
\text { whether or not to } \\
\text { enter (at cost c) } \\
\text {-Insider learns } \theta\end{array}$ & $\begin{array}{l}\text { Trading Period: } \\
\text {-Outsider submits } \\
\text { binding limited orders } \\
(\alpha, P) \\
\text {-Insider submit market } \\
\text { order } \mathrm{m}\end{array}$ & $\begin{array}{ll}\text { consumption } \\
\text { occurs } \\
\text { in } \\
1 \\
1\end{array}$ \\
\hline
\end{tabular}




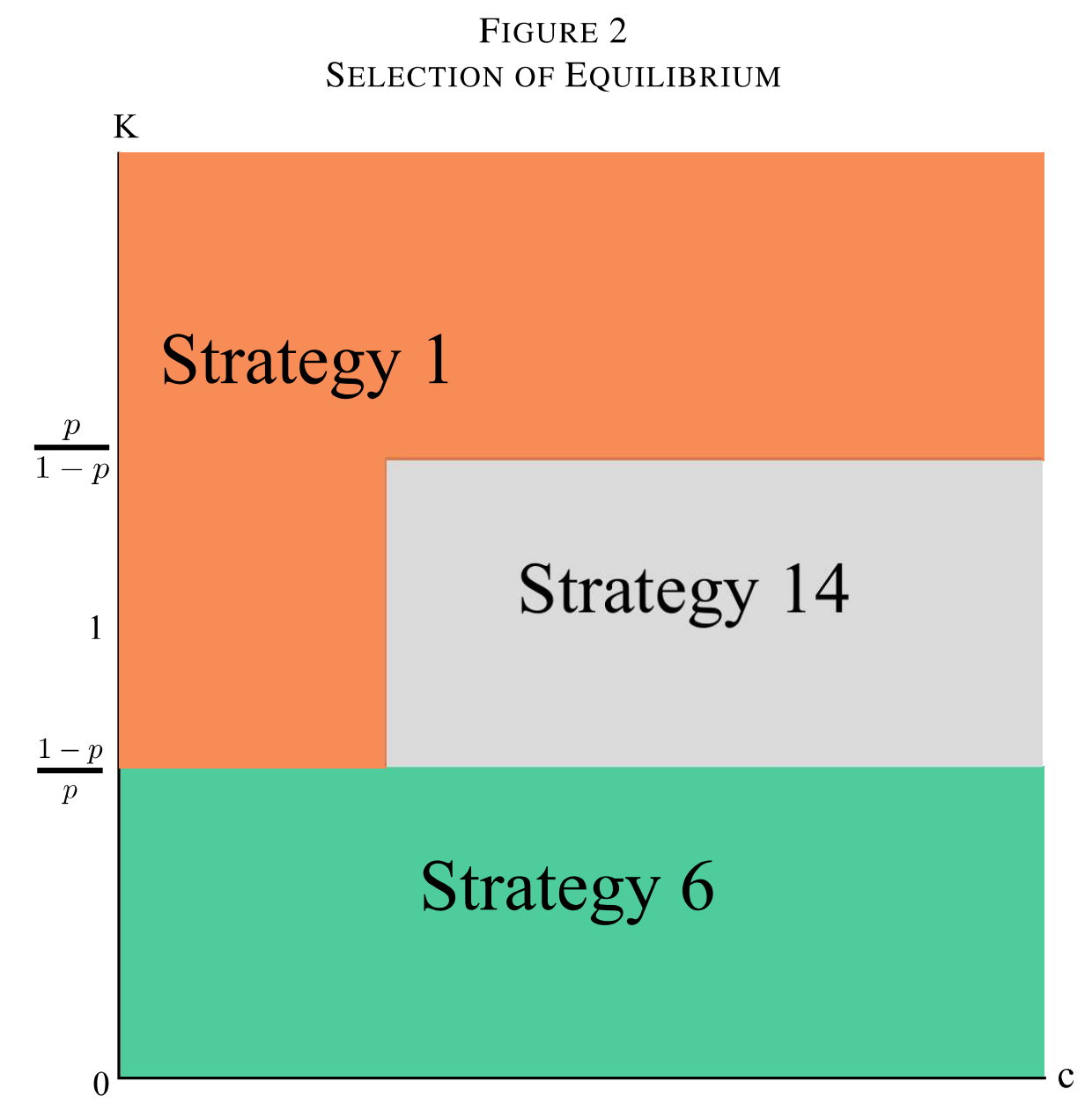

The yellow area represents strategy 1 , where the insider preannounces $\left(q_{1}, l_{1}\right)$ if he observes liquidity needs and $\left(q_{2}, l_{2}\right)$ otherwise. The grey area represents strategy 14 , where the insider preannounces $\left(q_{2}, l_{2}\right)$ if he observes $\left(1, \theta_{L}\right)$ and $\left(q_{1}, l_{1}\right)$ otherwise. The green area represents strategy 6 , where the insider preannounces $\left(q_{1}, l_{1}\right)$ if he observes $\left(1, \theta_{H}\right),\left(q_{2}, l_{2}\right)$ if he observes $\left(1, \theta_{L}\right)$, and $\left(q_{3}, l_{3}\right)$ otherwise. 